Document downloaded from:

http://hdl.handle.net/10251/141955

This paper must be cited as:

Tello-Oquendo, F.; Navarro-Peris, E.; Barceló Ruescas, F.; Gonzálvez-Maciá, J. (10-2). Semi-empirical model of scroll compressors and its extension to describe vapor-injection compressors. Model description and experimental validation. International Journal of Refrigeration. 106:308-326. https://doi.org/10.1016/j.ijrefrig.2019.06.031

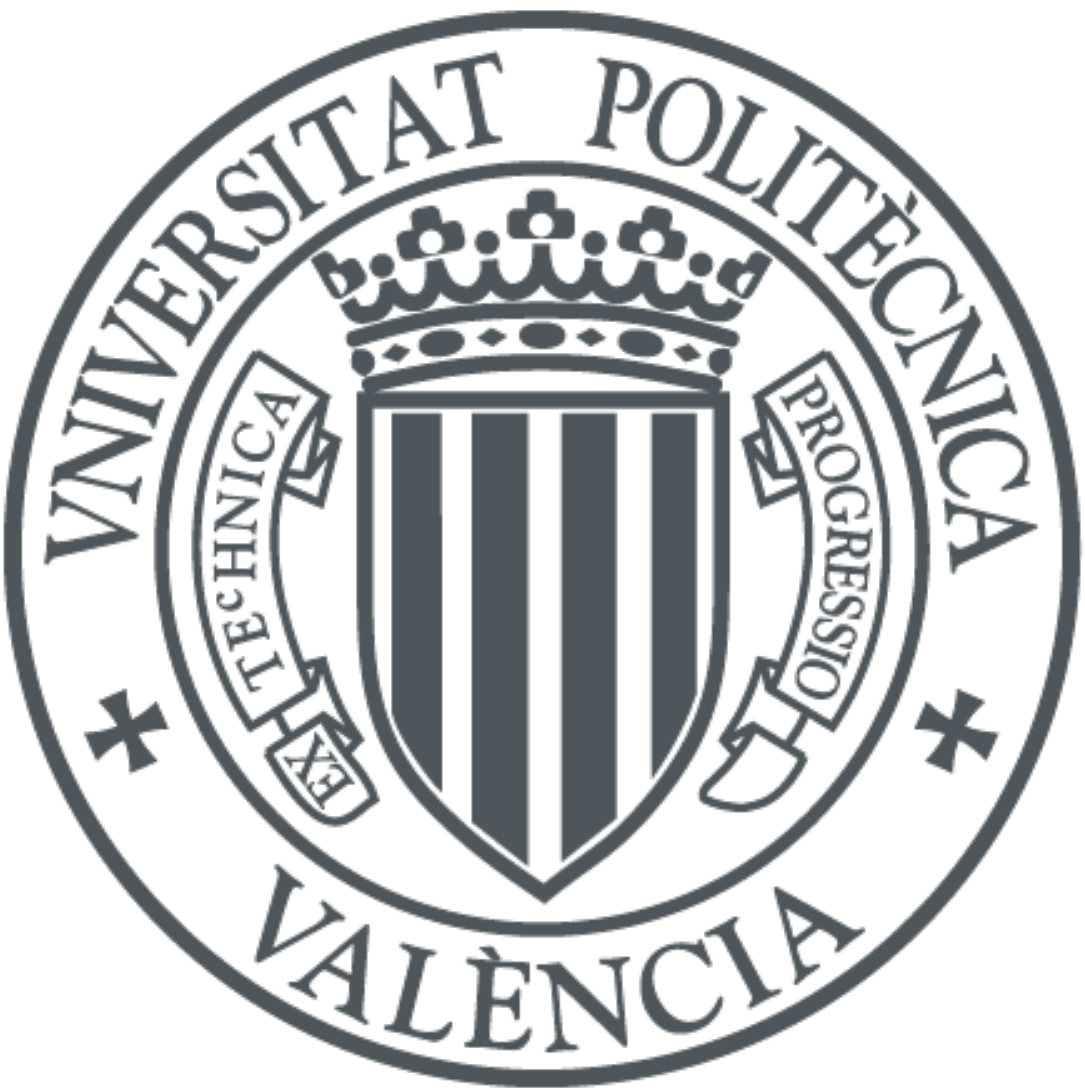

The final publication is available at

https://doi.org/10.1016/j.jjrefrig.2019.06.031

Copyright Elsevier

Additional Information 


\title{
Semi-empirical model of scroll compressors and its extension to describe vapor- injection compressors. Model description and experimental validation
}

Tello-Oquendo F.M., Navarro-Peris E., Barceló-Ruescas F., Gonzálvez-Maciá J., Semiempirical model of scroll compressor and its extension to describe vapor-injection compressors. Model description and experimental validation. International Journal of Refrigeration .

\begin{abstract}
This paper presents a semi-empirical model of scroll compressors and proposes a methodology in order to extend this model to vapor-injection scroll compressors. The model takes into account the ideal evolution of the refrigerant throughout the compressor and considers the main sources of losses in the compression process. The model is able to predict the compressor and volumetric efficiencies in terms of ten empirical parameters, which have a direct physical interpretation. For the model validation, a series of four non-injected scroll compressors of different capacities were tested using R-290 and a scroll compressor with vapor-injection (SCVI) was characterized using R-407C. Results show a correct agreement between the experimental and calculated compressor efficiencies, with a maximum deviation of $\pm 5 \%$. Furthermore, the model estimates accurately the discharge temperature of the refrigerant, compressor power input, and refrigerant mass flow rate in the suction and injection port. Finally, the SCVI model response was evaluated by varying the intermediate pressure and the injection superheat.
\end{abstract}

Keywords: scroll compressor; semi-empirical model; vapor-injection; experimental validation 


\section{Introduction}

Scroll compressors are widely used in commercial and residential air-conditioning, refrigeration and heat pump applications. This compressor technology is orbital motion, positive displacement machines that compress refrigerant gas using two inter-fitting, spiral-shaped scroll members. They have no dead space, the contact between the flanks of scrolls and in their bases and upper edges is almost perfect and constant; therefore, it has very good axial and radial compliance. Consequently, scroll compressors present several advantages such as high compressor and volumetric efficiencies, low vibrations and noise, low torque variations and leakage (ASHRAE Handbook, 2008).

Recent researches show a great interest in improving the efficiency of the refrigeration and heat pump systems and finding the appropriate configuration to optimize their performance, as well as defining the best control strategy. In order to analyze the performance of the systems, it would be useful to have a simple and precise tool to predict system behavior. The major component in the heat pump system is the compressor; therefore, compressor models play an important role in calculating the compressor performance for the systems optimization.

Depending on the model purpose and the available information about the compressor, several scroll compressor models were found in the literature. Byrne et al. (2014) presented a summary of the scroll compressor models. Three categories can be distinguished: geometrical models, semi-empirical models, and empirical models.

Geometrical models analyze all the processes involved in the compression process and try to describe the whole system in terms of the physical laws implied. These models are complex, the time of running is longer, and they require a number of boundary conditions and geometrical dimensions which are difficult to obtain from manufacturer catalogs.

Schein and Radermacher (2001) developed a detailed computer model to predict the performance of a scroll compressor including its efficiencies, power input, and mass flow rate for given operating conditions and scroll designs. The operating conditions and compressor's geometry (height, thickness, and pitch of the scrolls) are inputs for the model. The model includes the effects of internal leakage and over and under-compression.

Chen et al. (2002a, 2002b and 2009) presented a detailed model for the compression process of a scroll compressor. A geometrical study was conducted to define the areas and volumes of compressor chambers as a function of the orbiting angle. Governing mass and energy conservation equations were developed for each chamber. Refrigerant leakage and heat transfer with the scroll wrap were considered in the model. In the same line, Bell et al. (2012a) presented an extension of the model presented by Chen et al. and incorporated liquid flooding to the compressor and expander scroll models. The global model computes the mass flow rate, the average discharge temperature and enthalpy, the shaft power and the efficiencies of the machine. Moreover, experimental validation of the models (Bell et al., 2012b), and optimization of scroll compressors for large amounts of oil (Bell et al., 2012c) were presented.

Blunier et al. (2009) conducted a dynamical model of a scroll compressor. The compression process was described in detail and the estimation of the chamber volumes and the leakage between them were analyzed neglecting the heat transfers with the surrounding parts. Both the volume variation of the chambers and the leakage area were analyzed as a function of the orbiting angle. Tseng and Chang (2006) presented a design optimization of the scroll compressor using geometrical models. 
Among the geometrical compressor models, some of them have been developed in order to describe the performance of the scroll compressors with refrigerant injection. The refrigerant injection can either increase the capacity and COP of the system or decrease the discharge temperature of the compressor to extend its working envelope, especially for refrigeration systems working with low evaporating temperatures and heat pump systems working with high condensing temperatures. In those cases, the pressure ratio is large; consequently, both the isentropic and the volumetric efficiency of a non-injected compressor are affected; the discharge temperature increases compromising the integrity of the oil in the installation and limiting the working range of the compressor.

Wang et al. (2008) established and validated a geometrical model of scroll compressor with vapor-injection working with R-22 as refrigerant. The model included the description of scroll wraps, working chambers volume, and leakage areas. It was found that heat transfer between scroll wraps and the refrigerant and the back-pressure pocket configuration have little influence and can be ignored in the model; the refrigerant injection process in scroll compressors is a continual parameter-varying "adiabatic throttling + isobaric mixture" time-varying process. Based on this model, several studies have been derived. Wang et al. (2009c) numerically analyzed the effects of the refrigerant injection on the scroll compressor performance. The influence of the injection pressure and enthalpy, injection holes area and position on the compressor work, discharge temperature and volumetric efficiency were studied. Wang et al. (2009a) investigated the effect of vapor-injection on the system and components parameters in a two-stage R-22 cycle. Based on that analysis, general principles of design and operation of the refrigeration system were proposed.

As it was commented previously, in all these geometrical models, a detailed description of the compressor geometry is required; nevertheless, some internal dimensions of scroll wraps are difficult to obtain from catalogs. In addition, the implementation of geometrical models is complex, the calculation time is longer and the integration in the whole system model is not feasible due to the convergence problems with models of other components. In this context, semiempirical models can be an attractive alternative. Semi-empirical models are developed basing on experimental, or in turn on catalog data. They describe the system using some of its characteristic variables combined with some physical assumptions and empirical parameters. Even though they do not give detailed information about all the physical processes involved, they are useful to analyze the compressor performance operating under several working conditions and its influence on the system capacity and COP.

Semi-empirical models of compressors are used to assess the performance of a heat pump or a refrigerating system under several operating conditions. The modeling structure is validated by real compressor data. The output variables of the models are generally isentropic and volumetric efficiencies, mass flow rate, power input, and discharge temperature, in some cases.

Several semi-empirical models of scroll compressors were found in the literature. Winandy et al. (2002) worked on a simplified scroll compressor model based on the main processes affecting the refrigerant during compression. A fictitious isothermal wall was used to model heat exchanges within the compressor and between the compressor and the ambient. The model computes the mass flow rate, power input, discharge temperature, thermal capacities at suction heating up and discharge cooling-down and ambient losses. The model was validated with experimental data of a scroll compressor working with R-22 as refrigerant.

Several studies have been developed based on the model presented by Winandy et al. Among them, Duprez et al. (2007) and (2010) presented a modeling technique for reciprocating 
and scroll compressors. Some adaptations were made to this semi-empirical technique and accurate results were obtained, having average deviations less than $3 \%$ on mass flow rates and power consumptions for scroll compressors. Cuevas et al. (2012) tested and modeled an automotive electric scroll compressor working with R-134a as refrigerant. Byrne et al. (2014) presented a scroll compressor model for R-407C, which was adapted to hydrocarbons. A dimensional analysis was performed to adapt the model to other compressor sizes. The adaptation procedures of the model to other fluids and to other sizes were validated using R-407C and R290 as refrigerants. The validation was made in terms of mass flow rate, compressor power and discharge temperature with accuracies less than $\pm 10 \%, \pm 10 \%$, and $\pm 5 \mathrm{~K}$ respectively, under typical working conditions.

Navarro et al. (2007a) and (2007b) presented a semi-empirical model of reciprocating compressors that is able to predict compressor efficiency and volumetric efficiency in terms of a certain number of parameters (10) representing the main sources of losses inside the compressor. The model can be fitted from experimental data or only from catalog data. The model reproduces the compressor and volumetric efficiencies with deviation lower than $3 \%$ under a wide range of operating conditions. In addition, a series of compressors with different capacities and geometries working were analyzed with R-290 as refrigerant. The relative influence of the diverse compressor losses on the compressor efficiencies was estimated as a function of the operating conditions.

Semi-empirical models have also been developed for refrigerant injection scroll compressors. Winandy and Lebrun (2002) presented a semi-empirical model of a scroll compressor with vapor-injection and liquid refrigerant injection working with R-22 as refrigerant. The mass flow rate, compressor power, and discharge temperature of the compressor were predicted within $\pm 4 \%, \pm 4.5 \%, \pm 5 \mathrm{~K}$, respectively. The injection was assumed to be carried out just after the closure of the suction pocket. Leakage, suction, and discharge pressure drop were not considered in the model and no information about the validation of the predicted injection mass flow rate was given. Based on the former model, Dardenne et al. (2015) developed a semiempirical model of a variable speed scroll compressor with vapor-injection working with R-410A as refrigerant. The model requires 10 parameters fitted from experimental data to simulate the process that the refrigerant undergoes from suction and injection ports to discharge port. The model includes the leakage in the compression process and computes the suction and injection refrigerant mass flow rates, the compressor power, and the discharge temperature within $\pm 5 \%$, $\pm 10 \%, \pm 5 \%, \pm 5 \mathrm{~K}$, respectively.

On the other hand, empirical models are based on empirical correlations in which input data are related to the output data without describing any physical phenomena. The main advantages of these models are simplicity and speed of calculation, but they are mostly unable to predict the behavior of the system in non-tested conditions. They are useful for programming control systems or evaluating the system in conditions specified by some standard. These kind of models are the ones used by the ARHI and ISO normative in which a polynomial equation of 10 coefficients is obtained from quadratic fit from experimental data (ARHI Standard 540, 2015). Unlike empirical models, semi-empirical models can predict compressor performance with good accuracy when the compressor works under different operating points from those that were tested, and away from the work map. These models can be fitted using experimental data o only catalog data of compressors, and the predictions are more reliable than the empirical model results. In addition, semi-empirical models do not have high computational cost, they are easy to implement in more complex system models and do not require as many internal characteristics of the compressor as in geometric models. 
The current paper presents a semi-empirical model of scroll compressors and provides a methodology in order to extend this model to vapor-injection scroll compressors. The model is performed based on the phenomenological model for analyzing reciprocating compressors developed by Navarro et al. (2007a). Some modifications were included to adapt the model to scroll technology. The resulting model takes into account the ideal evolution of the refrigerant throughout the scroll compressor, considering the main sources of losses in the compression process.

In order to validate the compressor model, a series of four non-injected scroll compressors (SCNI) of different capacities were tested in a wide range of operating conditions using R-290 as refrigerant. In addition, a scroll compressor with vapor-injection (SCVI) was characterized using $\mathrm{R}-407 \mathrm{C}$ as refrigerant. All the compressors were tested in a calorimetric test bench.

The SCNI model is able to predict the compressor and volumetric efficiencies in terms of ten empirical parameters, which have a direct physical interpretation. At the same time, the model is able to predict the suction mass flow rate, the compressor power input, and the discharge temperature; additionally, the SCVI model can predict the injection mass flow rate.

Moreover, the SCVI model results were compared with the output data of the empirical correlations from the literature in terms of mass flow rate, compressor power input, and discharge temperature. Finally, the SCVI model response was evaluated by varying the intermediate pressure and the injection superheat to show the good predictive capability of the model.

The proposed model can be adjusted from catalog data of compressors and provide more information (discharge temperature) than the provided by empirical models, but with a smaller number of parameters.

\section{Model description}

The present compressor model aims to reproduce the compressor efficiency and the volumetric efficiency as a function of a set of parameters that can be obtained from experimental data or from correlations of standard characterization performance data (manufacturer's catalogs). These parameters have a physical background so that once they are correlated, the model can be used to predict the compressor performance under operating conditions which are not tested, that is the main advantage compared with empirical models.

Unlike previous semi-empirical models of the literature, this study attempts to move towards the goal of finding parameters that retain the maximum physical importance in the compression process. The values obtained from the model are expected to show a clear agreement with the reasonable orders of magnitude of the compressor characteristics they represent.

\subsection{Model assumptions}

The model assumes the refrigerant evolution through the compressor shown in the schematic and P-h diagram of Fig. 5.1. The refrigerant enters the compressor at point 1 (suction) and leaves the compressor at point 8 (discharge). The reference for the overall compressor efficiency is given by an isentropic condition from the inlet to the outlet of the compressor (8s). 


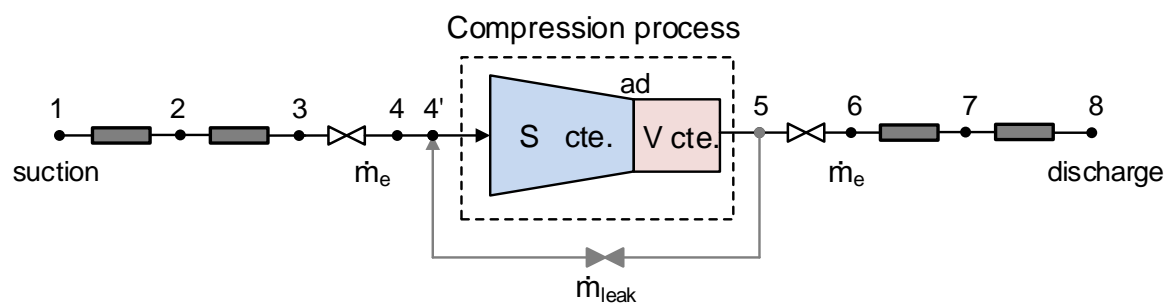

b)

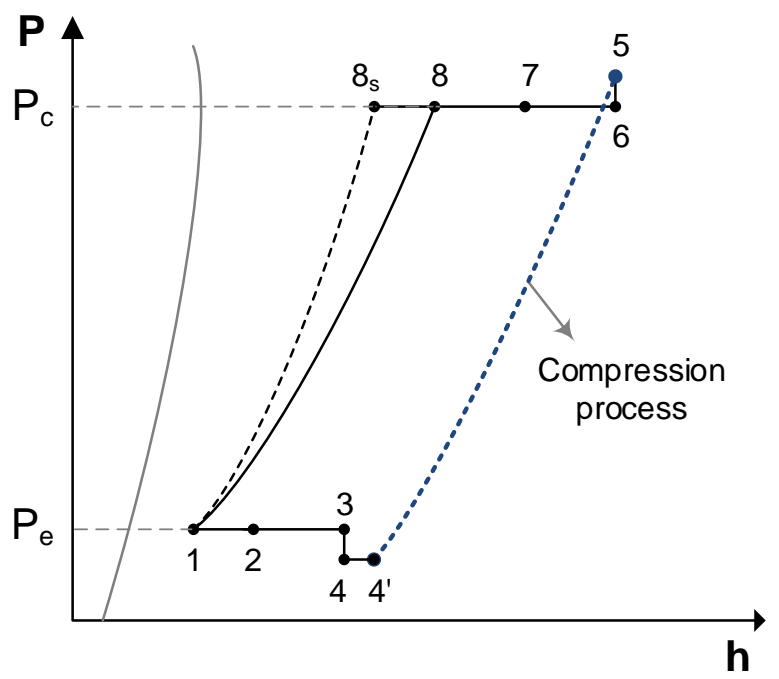

Fig. 0.1 Refrigerant evolution inside the scroll compressor. a) Model scheme. b) P-h diagram of the compression process.

The model assumes that the evolution of the refrigerant through the compressor can be divided into the following sequence of effects:

(1-2): Isobaric vapor heating due to motor cooling and mechanical loss dissipation.

(2-3): Isobaric vapor heating due to the heat transferred from the hot side of the compressor (discharge plenum) to the inlet flow.

(3-4): Isenthalpic pressure loss in the suction port.

(4-4'): Isobaric vapor heating due to leaks.

(4'-ad): Isentropic compression from the scrolls intake conditions (leaks appear in this part of the process) to the adapted pressure at the discharge port.

(ad-5): Isochoric compression from the adapted pressure to the discharge pressure $\left(\mathrm{P}_{\mathrm{c}}\right)$ at the discharge plenum.

(5-6): Isenthalpic pressure loss in the discharge port.

(6-7): Isobaric vapor cooling due to the heat transferred to the suction side.

(7-8): Heat loss to ambient through the compressor shell.

In the model, heat transfer to the oil is neglected.

Regarding the evolution from 4' to 5, scroll compression embodies a fixed, built-in volume ratio $(\varepsilon)$, which is defined by scroll geometry (Eq. (5.1)). This feature provides the scroll compressor with different performance characteristics than those of reciprocating or conventional rotary compressors. 


$$
\varepsilon=\frac{V_{s}}{V_{a d}}
$$

The built-in volume ratio $(\varepsilon)$ is not known a priori and it has to be identified. The known variable is the volume at the compressor suction $\left(\mathrm{V}_{\mathrm{s}}\right)$, which is provided by the compressor manufacturer. For a given refrigerant and determined operating conditions, there is a fixed internal pressure ratio corresponding to the built-in volume ratio. Therefore, if the external pressure ratio (defined by the working conditions of a given application) is different from the internal pressure ratio, the compressor is not adapted. In this context, three possible situations are distinguished, when the external pressure ratio $\left(\mathrm{P}_{\mathrm{r}}\right)$ is equal to the internal pressure ratio (adapted), when $\mathrm{P}_{\mathrm{r}}$ is higher to the internal pressure ratio (under-compression) and when $\mathrm{P}_{\mathrm{r}}$ is lower to the internal pressure ratio (over-compression). These three possible situations are illustrated in the P-V diagram of Fig. 5.2.

In the event of under-compression, extra work must be done in order to bring the refrigerant up to the pressure of the discharge plenum. Actually, this is a complex process consisting of backflow into the compression chamber and flow mixing occurring together as the discharge port opens to the discharge plenum. In this model, this phenomenon is assumed as instantaneous and is simplified as a constant volume work addition process as proposed by Winandy et al (2002). If a dynamic discharge valve is implemented, the back-flow into the compression chamber is reduced as well as the extra work associated with the recompression of the refrigerant (red shaded area in Fig. 5.2); nevertheless, in the present model, the effect of the dynamic discharge valve is not considered in the compression power estimation. In the event of the over-compression, pressure drop must occur in the discharge port by the refrigerant flowing from the final compression chamber into the discharge plenum, hence there is a work penalty associated with over-compression.

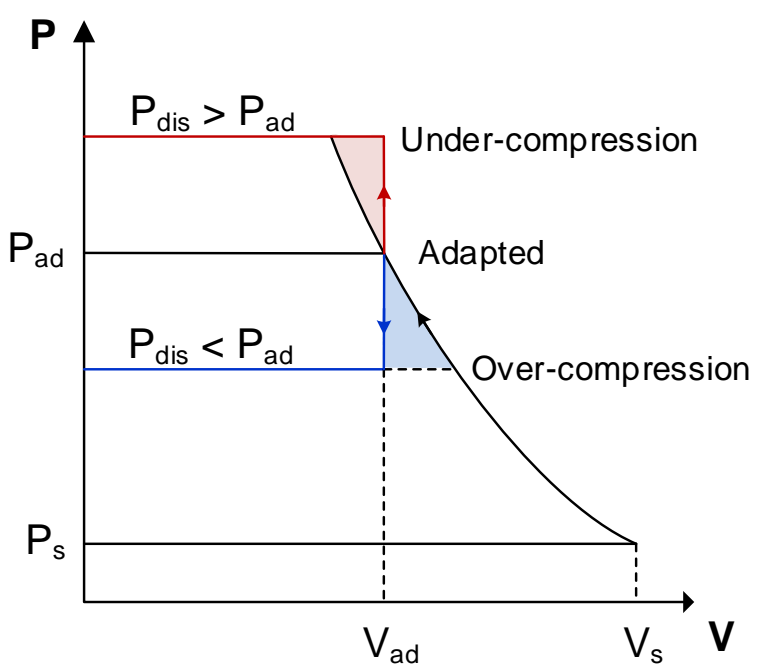

Fig. 0.2 P-V diagram of the compression process in a scroll compressor.

Because scroll compressor is a fixed volume ratio machine, it will compress the refrigerant to its design point regardless of the lower or higher pressure of the system. As a result, extra work 
is used to compress the refrigerant than would be needed if there were a match between the system and the compressor's pressure ratio. Fig. 5.2 shows the extra work when the compressor is not adapted as shaded triangular areas, for under and over-compression. The expression used to estimate the internal compression work is detailed in section 5.2.4.6.

The mass flow rate is calculated with Eq. (5.2), where $\eta_{\mathrm{v}}$ represents the volumetric efficiency, $\dot{V}_{S}$ is the swept volume of the compressor defined by the Eq. (5.3), $\rho_{1}$ is the density at the compressor inlet, and $n$ represent the compressor speed.

$$
\begin{gathered}
\dot{m}_{e}=\eta_{v} \dot{V}_{s} \rho_{1} \\
\dot{V}_{s}=n V_{s}
\end{gathered}
$$

\subsection{Leakage}

In scroll compressors, there are two primary leakage paths namely, radial and flank or tangential leakage. Radial leakage occurs at the clearance between the bottom or the top plate and the scrolls wraps. The other path, flank leakage, occurs at the clearance between the flanks of the two scrolls wraps. The leakages increase the energy consumption because the refrigerant which flows from a high-pressure chamber to a low-pressure chamber will be compressed again, consequently, the re-compression associated with leakage process degrades the compressor's isentropic efficiency and also decreases the volumetric efficiency.

In this study, all the internal leakages (flank and radial) that occur continually in the compressor as the compression proceeds are modeled using Eq. (5.4). This equation refers to the isentropic flow of the compressible gas through a simple convergent nozzle, according to Lemort (2008) and Giuffrida (2014).

$$
\begin{gathered}
\dot{m}_{\text {leak }}=A_{\text {leak }} \rho_{\left(P_{\text {thr,leak }}, S_{5}\right)} \sqrt{2\left(h_{5}-h_{\left(P_{\text {thr,leak }}, S_{5}\right)}\right)} \\
P_{\text {thr,leak }}=\max \left[P_{4}, P_{\text {crit,leak }}\right]=\max \left[P_{4}, P_{5}\left(\frac{2}{\gamma_{5}+1}\right)^{\frac{\gamma_{5}}{\gamma_{5}+1}}\right] \\
\dot{m}_{e} h_{4}+\dot{m}_{\text {leak }} h_{5}=\left(\dot{m}_{e}+\dot{m}_{\text {leak }}\right) h_{4 \prime}
\end{gathered}
$$

In Eq. (5.4), $\mathrm{A}_{\text {leak }}$ is a parameter of the model that represents the cross-sectional area of the leakage nozzle throat. The throat pressure $\left(\mathrm{P}_{\text {thr,leak }}\right)$ is calculated by Eq. (5.5), considering the leaked refrigerant as a perfect gas and taking the maximum between the actual pressure at nozzle outlet $\left(\mathrm{P}_{4}\right)$ and the critical pressure $\left(\mathrm{P}_{\text {crit,leak }}\right)$. Eq. (5.5) is introduced in order to consider that choked flow may occur in the nozzle throat since the ratio between actual inlet nozzle pressure to actual nozzle discharge pressure could be greater than the critical one, depending on the compressor operating conditions (Dardenne et al., 2015).

A mixing process must occur between the suction refrigerant flow and the refrigerant leaked from high-pressure sides. In the model, two assumptions are made in the mixing process analysis. The first is that the mixing process occurs in the suction chamber as shown in Fig. 5.1a. The second assumption is that mixing is an isobaric and adiabatic process. The mixed enthalpy of the refrigerant mixture that enters in the compressor is calculated by Eq. (5.6). 
The compressor power input $(\dot{E})$ can be assumed to be the internal work of compression $\left(\dot{W}_{4^{\prime}-5}\right)$ to change the refrigerant from state 4' to state 5 plus the energy that the compressor consumes in mechanical ( $\left.\dot{E} L_{\text {mech }}\right)$ and electrical losses. Hence, $\dot{E}$ can be expressed by Eq. (5.7).

$$
\dot{E}=\frac{1}{\eta_{e l}}\left(\dot{W}_{4^{\prime}-5}+\dot{E} L_{m e c h}\right)
$$

\subsection{Compressor efficiencies}

The corresponding expressions for volumetric and overall compressor efficiencies are:

$$
\begin{gathered}
\eta_{v}=\frac{\dot{m}_{e}}{\dot{V}_{s} \rho_{1}} \\
\eta_{c}=\frac{\dot{m}_{e}\left(h_{8 s}-h_{1}\right)}{\dot{E}}
\end{gathered}
$$

The overall compressor efficiency (Eq. (5.9)) represents a ratio between the ideal isentropic power consumption and the real indicated work for the compressor. Where $\mathrm{h}_{8 \mathrm{~s}}$ represents the enthalpy at the compressor discharge pressure considering an isentropic compression from the compressor inlet condition (see point 1 in Fig. 5.1).

\subsection{Compressor losses}

2.4.1 Vapor heating due to mechanical loss dissipation and motor cooling

The heating of the inlet refrigerant by mechanical loss dissipation and motor cooling is quantified by Eq. (5.10), where $\mathrm{Z}_{\mathrm{el}}$ and $\mathrm{Z}_{\mathrm{mech}}$ are fractions of the losses transferred to the suction vapor as heat. It is assumed that the fraction of absorbed heat is the same for both losses, that is $\mathrm{Z}_{\mathrm{el}}=\mathrm{Z}_{\mathrm{mech}}$, so these factors can be renamed as $\mathrm{K}_{1}$ parameter. The remaining heat is released to the environment either through the outlet gases or through the compressor shell. The temperature increase (1-2) of the suction vapor is given by Eq. (5.11).

$$
\begin{gathered}
\dot{Q}_{1-2}=\left(1-\eta_{e l}\right) \dot{E} Z_{e l}+\dot{E} L_{m e c h} Z_{m e c h} \\
\Delta T_{1-2}=\frac{\dot{Q}_{1-2}}{\dot{m}_{e} C_{p 1}}=K_{1}\left(\frac{\left(1-\eta_{e l}\right)}{\eta_{c}} \frac{h_{8 s}-h_{1}}{C_{p 1}}+\frac{\dot{E} L_{m e c h}}{\eta_{v} \dot{V}_{s} \rho_{1} C_{p 1}}\right)
\end{gathered}
$$

2.4.2 Vapor heating due to heat transferred from the hot side of the compressor (discharge plenum) to the inlet flow

Heat transfer in scroll compressors is a complex process that includes the inlet and exhaust heat transfer and the scroll-gas heat transfer. The mechanical losses heat the scrolls and the shell resulting generally in heat transfer from them to the refrigerant gas. During the compression process, the scrolls are at a different temperature than the gas that is in contact with them, so the heat transfer from the scrolls to the gas will depend on exact operating conditions. The local heat transfer coefficient and the temperatures of the scrolls wraps and the top and bottom plates are 
needed in order to calculate the heat transfer rate. These data are dependent on the scroll wraps geometry and the rotational speed. Nevertheless, the dimensions and geometric characteristics of the scroll wraps are not available from the manufacturer data. In this context, in order to take into account the heat transfer effect in the compression process, some simplifications have been made in the model. The model considers that the total heat transfer occurs from the hot side of the compressor (discharge plenum) to the inlet flow. Hence, before leaving the compressor, the hot vapor flowing in the discharge plenum heats the refrigerant at the low-pressure side. As a first approximation, the heat transferred between both sides can be given by Eq. (5.12), where the temperature difference $\left(\mathrm{T}_{8 \mathrm{~s}}-\mathrm{T}_{1}\right)$ calculated from the ideal isentropic process is considered as an effective temperature difference, characteristic of the process.

The overall heat transfer coefficient (UA)ht is related to the heat transfer coefficient $h_{h t}$ using these approximations:

- $\mathrm{U}_{\mathrm{ht}}$ is assumed proportional to the heat transfer coefficient $\mathrm{h}_{\mathrm{ht}}, \mathrm{U}_{\mathrm{ht}}=\mathrm{C}^{\prime} \mathrm{h}_{\mathrm{ht}}$.

- The heat transfer coefficient $h_{h t}$ is assumed as the one given for the turbulent internal flow in a circular tube conforms to the Dittus-Boelter equation (Nellis and Klein, 2009).

Considering these approximations, the temperature increase (2-3) is given by Eq. (5.13), where $D_{h}$ is the hydraulic diameter characteristic, $A$ is the heat transfer area between discharge and suction plenum. Due to there is no information about geometrical dimensions, the diameter $\left(\mathrm{D}_{\mathrm{h}}\right)$, the area (A) and the constants $\mathrm{C}$ and $\mathrm{C}^{\prime}$ are grouped in a new parameter $K_{2}=A . C . C^{\prime} / D_{h}{ }^{1.8}$.

$$
\begin{gathered}
N u=C R e^{0.8} P_{r}^{0.4} \rightarrow h_{h t}=\frac{k}{D_{h}} C\left(\frac{\eta_{v} \dot{V}_{s} \rho_{1}}{D_{h} \mu}\right)^{0.8}\left(\frac{\mu C_{p}}{k}\right)^{0.4} \\
\Delta T_{2-3}=A C C^{\prime} \frac{\left(T_{8 s}-T_{1}\right)}{\left(\eta_{v} \dot{V}_{s} \rho_{1}\right)^{0.2}} \frac{k_{2}^{0.6}}{D_{h}^{1.8} C_{p}^{0.6} \mu_{2}^{0.4}}=K_{2} \frac{\left(T_{8 s}-T_{1}\right)}{\left(\eta_{v} \dot{V}_{s} \rho_{1}\right)^{0.2}} \frac{k_{2}^{0.6}}{C_{p}^{0.6} \mu_{2}^{0.4}}
\end{gathered}
$$

\subsubsection{Isenthalpic pressure losses in the suction port}

The suction pressure drop is estimated by Eq. (5.14), where $w_{3}$ is the inlet flow velocity and $A_{c h}$ is the effective area of the suction port. Finally, the drag factor $\xi_{3}$ and $A_{c h}$ is grouped in a new parameter $K_{3}=\xi_{3} / 2 A_{c h, 3}^{2}$.

$$
\Delta P_{3-4}=\xi_{3} \rho_{3} \frac{w_{3}^{2}}{2}=\xi_{3} \rho_{3} \frac{\left(\eta_{v} \dot{V}_{s}\right)^{2}}{2 A_{c h, 3}^{2}}=K_{3} \rho_{3}\left(\eta_{v} \dot{V}_{s}\right)^{2}
$$

\subsubsection{Isenthalpic pressure losses at the discharge port}

Using the same approach as in the suction, the pressure losses at the discharge port is given by Eq. (5.15), where $K_{4}=\xi_{5} / 2 A_{c h, 5}^{2}$, and $A_{c h, 5}$ is the effective area of the discharge port.

$$
\Delta P_{5-6}=K_{4} \rho_{5}\left(\frac{\rho_{4}}{\rho_{5}} \eta_{v} \dot{V}_{s}\right)^{2}
$$




\subsubsection{Mechanical losses}

According to ASHRAE Toolkit (Bourdhouxhe et al., 1994), the mechanical losses can be considered as a sum of two terms, one proportional to the compressor power input and the other dependent to the compressor speed.

$$
\dot{E} L_{\text {mech }}=K_{5} \dot{E}+K_{6} n^{2}
$$

\subsubsection{Internal work of compression}

As it was commented previously, the internal work of compression $\left(\dot{W}_{4^{\prime}-5}\right)$ is divided into two parts, the first one considers an isentropic compression up to the adapted pressure, and the second one considers a compression at constant absolute volume up to the discharge pressure, using the Eq. (5.17).

$$
\dot{W}_{4^{\prime}-5}=\left(\dot{m}_{e}+\dot{m}_{l e a k}\right)\left(h_{a d}-h_{4^{\prime}}\right)+n V_{a d}\left(P_{5}-P_{a d}\right)
$$

\subsubsection{Heat transfer to ambient}

The heat transfer towards the environment can be calculated using Eq. (5.18), where $T_{a m b}$ is assumed constant and equal to $35{ }^{\circ} \mathrm{C}$. The temperature of the compressor shell is assumed the corresponding to state 7, see Fig. 5.1. The overall heat transfer coefficient $\mathrm{UA}_{\mathrm{amb}}$ is a parameter of the model. The discharge temperature is the corresponding to the state 8 . The decrease of temperature (7-8) is estimated by Eq. (5.19).

$$
\begin{gathered}
\dot{Q}_{a m b}=\varepsilon_{\text {shell }} \dot{C}_{\text {min }}\left(T_{\text {shell }}-T_{a m b}\right)=\left(1-\exp \left(-\frac{U A_{a m b}}{\dot{C}_{7-8}}\right)\right) \dot{C}_{7-8}\left(T_{7}-T_{a m b}\right) \\
\Delta T_{7-8}=\frac{\dot{Q}_{a m b}}{\dot{m}_{e} C_{p 7}}=\frac{U A_{a m b}\left(T_{7}-T_{a m b}\right)}{\dot{m}_{e} C_{p 7}}
\end{gathered}
$$

The temperature at state 7 is determined after the isobaric vapor cooling due to the heat transferred to the suction side, by assuming that $\dot{Q}_{2-3}=\dot{Q}_{6-7}$.

For the adjustment of the $\mathrm{UA}_{\mathrm{amb}}$ parameter, it is necessary to know the discharge temperature of the compressor. In case of not knowing it, as in the case of adjustment based on catalog data, it can be estimated based on reference values of other compressors available in the literature. However, in the reference (Navarro et al., 2007a) the discharge temperature of the compressor was estimated by considering negligible the $\mathrm{UA}_{\text {amb }}$ parameter. Results showed that the estimation of the discharge temperature is actually quite good for low and medium pressure ratios where the temperature of the refrigerant is not high, and it is worse at high-pressure ratios, where the temperature of the refrigerant is higher. In any case, the use of a $\mathrm{UA}_{\text {amb }}$ will always improve the estimation of the discharge temperature. 


\subsection{Determination of the model's parameters}

To formulate the global model, the equations governing the different losses described in the previous sections are implicitly introduced in equations (5.8) and (5.9). Hence, Eqs. (5.6), (5.11), (5.13) - (5.15) are used to calculate the refrigerant states at points 4 and 5; Eq. (5.4) is used for calculating of mass flow rate, and Eqs. (5.16) and (5.17) are used for calculating compressor power consumption. This leads to a system of two implicit equations for the compressor and volumetric efficiencies, Eqs. (5.20) and (5.21), where $K=\left(K_{l}, \ldots, K_{6}\right), \eta_{e l}, \varepsilon, A_{\text {leak, }}$ and $U A_{a m b}$ represent compressor design parameters.

$$
\begin{aligned}
& f_{1}\left(\eta_{c}, \eta_{v}, \boldsymbol{K}, \eta_{e l}, A_{\text {leak }}, U A_{a m b}, \varepsilon, \dot{V}_{s}, P_{1}, P_{8}, S H\right)=0 \\
& f_{2}\left(\eta_{c}, \eta_{v}, \boldsymbol{K}, \eta_{e l}, A_{\text {leak }}, U A_{a m b}, \varepsilon, \dot{V}_{s}, P_{1}, P_{8}, S H\right)=0
\end{aligned}
$$

A set of data for an $\mathrm{N}$ number of working conditions obtained from experiments or from manufacturer catalogs is required to obtain the proper value of $K, \eta_{e l}, \varepsilon, A_{\text {leak }}$ and $U A_{a m b}$ by fitting procedure. To select the best combination parameters an error function was defined (Eq. (5.22)).

$$
\text { Error }=\frac{\sqrt{\sum_{i=1}^{N}\left[\left(\Delta \eta_{c, i}\right)^{2}+\left(\Delta \eta_{v, i}\right)^{2}\right]}}{N}
$$

The set parameters with a lower value of Error is selected as solution of the fitting process. The results shown in this paper were obtained by using the conjugate gradient method in multidimensions (Press et al., 2007). The compressor model was implemented in EES software (Klein and Alvarado, 2017). Once all the compressor design parameters are known, the system of two equations can be solved for the compressor and volumetric efficiencies for a given working condition $\left(\mathrm{P}_{1}, \mathrm{P}_{8}, \mathrm{SH}\right)$.

\subsection{Vapor-injection modeling methodology}

Once the semi-empirical model of scroll compressors is established, a simplified methodology to extend the model to vapor-injection scroll compressors (SCVI) is presented in this section. Some adaptations are incorporated into the model described in section 5.2.1 in order to include refrigerant injection in the compression process.

The relation between the injection ratio $\left(\dot{m}_{i n j} / \dot{m}_{e}\right)$ and the intermediate pressure ratio $\left(P_{\text {int }} / P_{e}\right)$ is an intrinsic characteristic of SCVI because it depends on the design, manufacturing and the injection port location of the compressor. In a previous work (Tello-Oquendo et al., 2017); the authors identified the relation between the injection ratio and the intermediate pressure ratio, independently of the injection mechanism used in the system (flash tank, internal heat exchanger or economizer). The correlation obtained is the Eq. (5.23). Based on the experimental data, the coefficients A and B can be obtained by linear regression. This correlation was tested for several intermediate pressure levels for a given injection superheat.

$$
\frac{\dot{m}_{i n j}}{\dot{m}_{e}}=A+B \frac{P_{i n t}}{P_{e}}
$$


In the present model, refrigerant injection is included in the model by using the correlation (5.23). The correlation allows estimating the injection mass flow rate as a function of the intermediate pressure for given suction conditions $\left(\dot{\mathrm{m}}_{\mathrm{e}}, \mathrm{P}_{\mathrm{e}}\right)$.

Refrigerant injection in scroll compressors is a complex process because of the continual variation of the pressure and volume in the compression chamber during injection (Wang et al., 2008, 2009a, and 2009c). In the present model, this complex process is simplified as instantaneous isobaric mixing at the intermediate pressure. Therefore, the model assumes that the compression process is composed of the following sequence of effects:

(4'-9): Isentropic compression from the scrolls intake conditions (leaks appear in this part of the process) to the intermediate pressure.

(9-10) Isobaric mixture of the suction mass flow rate $\left(\dot{m}_{\mathrm{e}}\right)$ and the injection mass flow rate $\left(\dot{\mathrm{m}}_{\mathrm{inj}}\right)$ at the intermediate pressure.

(10-ad): Isentropic compression from the mixture conditions at the intermediate pressure to the adapted pressure at the discharge port.

(ad-5): Isochoric compression from the adapted pressure $\left(\mathrm{P}_{\mathrm{ad}}\right)$ to the discharge pressure $\left(\mathrm{P}_{\mathrm{c}}\right)$ at the discharge plenum.

Fig. 5.3 depicts a P-h diagram with the evolution of the refrigerant in assumed by the model. The reference for the compressor efficiency is given by an isentropic condition from the inlet to the outlet of the compressor $\left(8_{\mathrm{s}}\right)$ for the suction mass flow rate, and by an isentropic condition from the injection (inj) to the discharge pressure $\left(11_{\mathrm{s}}\right)$ for the injected mass flow rate. The real conditions at the outlet of the compressor are indicated by state 8 in Fig. 5.3.

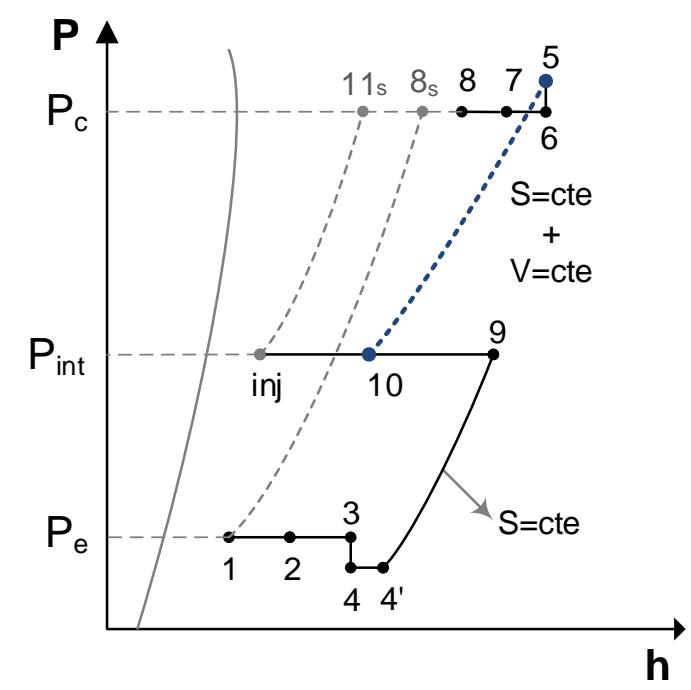

Fig. 0.3 P-h diagram of the refrigerant evolution inside the vapor-injection scroll compressor.

The volumetric efficiency is defined by Eq. (5.8), and the overall compressor efficiency is defined by Eq. (5.24). The enthalpy at the mixing point 10 is estimated by the Eq. (5.25), and the internal work of compression $\left(\dot{W}_{4^{\prime}-5}\right)$ by the Eq. (5.26). The thermophysical properties of the 
refrigerant at the different points are calculated with the NIST REFPROP database (Lemmon et al., 2010).

$$
\begin{gathered}
\eta_{c}=\frac{\dot{m}_{e}\left(h_{8 s}-h_{1}\right)+\dot{m}_{i n j}\left(h_{11 s}-h_{i n j}\right)}{\dot{E}} \\
\left(\dot{m}_{e}+\dot{m}_{i n j}\right) h_{10}=\dot{m}_{e} h_{9 s}+\dot{m}_{i n j} h_{i n j} \\
\dot{W}_{4^{\prime}-5}=\left(\dot{m}_{e}+\dot{m}_{l e a k}\right)\left(h_{9}-h_{4^{\prime}}\right)+\left(\dot{m}_{e}+\dot{m}_{i n j}+\dot{m}_{l e a k}\right)\left(h_{a d}-h_{10}\right) \\
+n V_{a d}\left(P_{5}-P_{a d}\right)
\end{gathered}
$$

To formulate the global model of the SCVI, the coefficients A and B of correlation (5.23) are added to the two implicit equations for the compressor and volumetric efficiencies (Eqs. (5.20), (5.21)). A set of data for an $\mathrm{N}$ number of working conditions obtained from experiments or from manufacturer catalogs is required to obtain the proper value of the compressor parameters by fitting procedure. The error function used is Eq. (5.22). Once all the compressor design parameters are known, the system of two equations can be solved for the compressor and volumetric efficiencies for a given working condition $\left(\mathrm{P}_{1}, \mathrm{P}_{8}, \mathrm{SH}, \mathrm{SH}_{\mathrm{inj}}\right)$.

In the present model, each model parameter is related to a source of losses considered in the compression process in a separate way. This model feature allows evaluating, although not in an exact way like in geometrical models, the possible influence of the losses in compressor performance under different working conditions.

\section{Experimental setup and test procedure}

The experimental setup consists of a calorimetric test bench, which was modified to add the injection line (Tello-Oquendo et al., 2017). Fig. 5.4 shows the scheme of the test bench used for testing scroll compressors (with and without vapor-injection).

The compressors testing procedure was performed based on the European Standard EN 13771-1 (2016). The test bench is able to control the operating conditions (pressure and temperature) of the compressors at the suction, discharge and injection ports. The secondary refrigerant calorimeter method was chosen as the primary test procedure to measure the mass flow rate, and the confirming test method was performed using a Coriolis-type mass flow meter.

The condenser mass flow rate is directly measured using a Coriolis-type (FisherRosemount Micro-Motion CMF025M), C-1 in Fig. 5.4. The instrument accuracies of pressure transmitter (Fisher-Rosemount 3051) and temperature transmitter (RTD-PT 100) are 0.02\% and $0.05{ }^{\circ} \mathrm{C}$, respectively.

The intermediate pressure and the injection temperature are controlled independently. The intermediate pressure is controlled by an electronic expansion valve (EEV-1). The injection mass flow rate is vaporized in a heat exchanger using a secondary circuit of a water-glycol mixture. The temperature of the water-glycol mixture is controlled by electric resistors. The injection line (gray line in Fig. 5.4) is equipped with a Coriolis-type mass flow meter with uncertainty of \pm 0.025 $\mathrm{g} \mathrm{s}^{-1}$ (C-2 in Fig. 5.4), a pressure transducer with a precision of $0.2 \%$, an RTD with a precision of $0.1 \mathrm{~K}$, an electrovalve located before the expansion valve (EEV-1), and an electrical power meter with a precision of $0.1 \%$. 


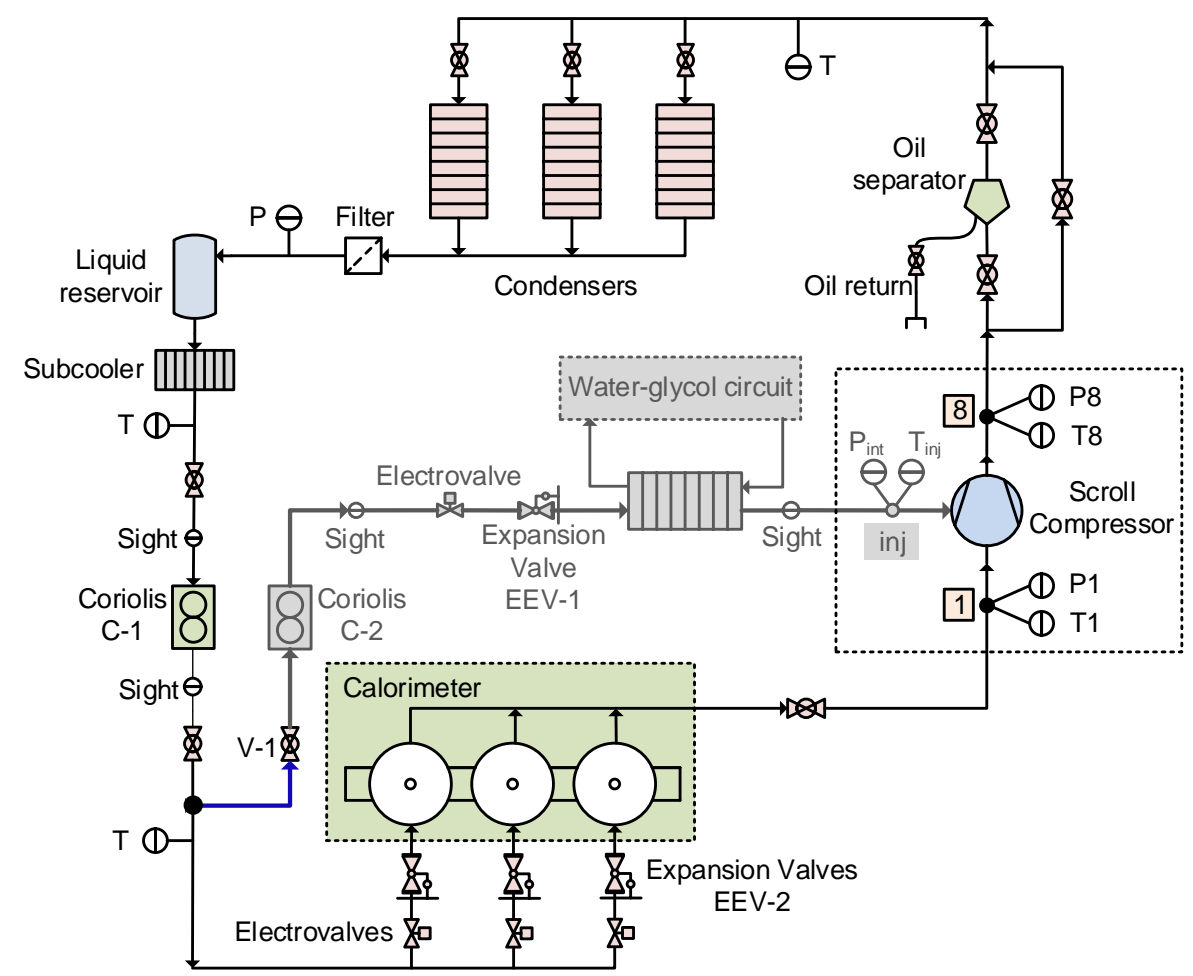

Fig. 0.4 Scheme of the calorimetric test bench.

For SCVI, the evaporator mass flow rate is calculated with Eq. (5.27) and is compared with the secondary refrigerant calorimeter based result.

$$
\dot{m}_{e}=\dot{m}_{c}-\dot{m}_{i n j}
$$

The SCVI testing procedure begins with the setting of the condensing pressure, evaporating pressure and the superheat at the compressor inlet acting on the flow rate of the water condenser, valves EEV-2, and resistors of the calorimeter, respectively. The electronic expansion valve (EEV-1) regulates the intermediate pressure and the injection superheat is fixed with the waterglycol temperature through a heat exchanger (see Fig. 5.4)

Once the system is in equilibrium, the total mass flow rate $\left(\dot{\mathrm{m}}_{\mathrm{c}}\right)$, the injection mass flow rate $\left(\dot{\mathrm{m}}_{\mathrm{inj}}\right)$ and the compressor power input are measured. In addition, the injection temperature $\left(\mathrm{T}_{\mathrm{inj}}\right)$, and the condenser outlet temperature are registered. To test the non-injected scroll compressors (SCNI), the injection line is disabled by closing a ball valve (V-1).

Safety was a major concern during the design of the test facility. Specific procedures and standards regarding the handling and use of flammable gasses were taken into account (European Standard EN 378, 2017). Specific measures included the use of intrinsically safe electric material, specific propane sensors, the use of emergency switches and alarms and appropriate air renewal procedures to ensure no-critical concentrations in the case of leakage (European Standards: EN 60079-14, 2014; EN 60079-15, 2010; EN 60335-2-34, 2013; EN 60335-2-40, 2003).

In order to evaluate the scroll compressor models, a series of four SCNI of different capacities were tested working with R-290 as refrigerant. In addition, an SCVI was tested with $\mathrm{R}-407 \mathrm{C}$ as a refrigerant. The characteristics of the tested compressors are shown in Table 5.1. 
Table 0.1 Tested compressors.

\begin{tabular}{c|c|c|c|c}
\hline Compressor & Type & $\mathbf{V}_{\mathbf{s}}\left(\mathbf{c m}^{\mathbf{3}} \mathbf{r e v}^{\mathbf{- 1}}\right)$ & $\dot{\mathbf{V}}_{\mathbf{s}}\left(\mathbf{m}^{\mathbf{3}} \mathbf{h}^{\mathbf{- 1}}\right) @ \mathbf{5 0 ~ H z}$ & Refrigerant \\
\hline C15 & No-injection & 34 & 5.9 & R-290 \\
C21 & No-injection & 46 & 8 & R-290 \\
C30 & No-injection & 67 & 11.7 & R-290 \\
C38 & No-injection & 82 & 14.2 & R-290 \\
SCVI & Vapor-injection & 98 & 17.1 & R-407C \\
\hline
\end{tabular}

Table 5.2 shows the test matrix for the tested compressors. Labels "a" and " $b$ " correspond to the test points used for model fitting and model validation of the non-injected compressors. The parameters used in the SCNI testing was $10 \mathrm{~K}$ of superheat at the compressor suction and 5 K of subcooling at the condenser outlet. Labels "c" and "d" correspond to the test points used for model fitting and model validation of the SCVI. For the fitting points, $5 \mathrm{~K}$ of superheat was fixed in the compressor suction, and for the validation points, $10 \mathrm{~K}$ of suction superheat was fixed; in both cases, an injection superheat of $5 \mathrm{~K}$ was used. Labels "e" represent the test points for the intermediate pressure analysis and label " $\mathrm{f}$ " represents the test point for the injection superheat analysis. The test points were selected as a function of the compressor working envelope of the manufacturer and considering operating conditions for heating applications, see Fig. 5.5.

Table 0.2 Test matrix for the scroll compressors.

\begin{tabular}{|c|c|c|c|c|c|c|c|c|c|c|c|c|c|c|}
\hline \multirow{2}{*}{$\begin{array}{c}\mathbf{T}_{\mathbf{c}} \\
\left({ }^{\circ} \mathbf{C}\right) \\
\end{array}$} & \multicolumn{14}{|c|}{$\mathrm{T}_{\mathrm{e}}\left({ }^{\circ} \mathrm{C}\right)$} \\
\hline & -25 & -20 & -17 & -10 & -8 & -7.5 & -5 & -3 & 0 & 2 & 5 & 7.5 & 10 & 15 \\
\hline 20 & & & & a & & & & & & & & & & \\
\hline 35 & & $\mathrm{a}$ & & $\mathrm{a}$ & & & & & $\mathrm{a}$ & & & & & \\
\hline 40 & $\mathrm{c}$ & c & & $c$ & d & & $\mathrm{b}$ & & $\mathrm{c}$ & & & & $\mathrm{c}$ & \\
\hline 45 & & & & $\mathrm{~b}$ & & & $\mathrm{~b}$ & & & & & & & \\
\hline 50 & c & $\mathrm{c}, \mathrm{e}$ & d & $\begin{array}{c}\mathrm{a}, \mathrm{c}, \\
\mathrm{e}\end{array}$ & $\mathrm{d}, \mathrm{f}$ & b & & $\mathrm{d}$ & $\begin{array}{l}\mathrm{a}, \\
\mathrm{c}, \\
\mathrm{e}\end{array}$ & d & b & $\mathrm{a}$ & c & $\mathrm{a}$ \\
\hline 55 & & & & & & & $\mathrm{~b}$ & & & & & $\mathrm{~b}$ & & \\
\hline 60 & & $\begin{array}{c}\mathrm{c}, \mathrm{d} \\
\mathrm{e}\end{array}$ & & $\mathrm{c}, \mathrm{e}$ & d & & & & c & & b & & $\mathrm{c}, \mathrm{d}$ & \\
\hline 65 & & & & & & & & & $\mathrm{a}$ & & & $\mathrm{a}$ & & $\mathrm{a}$ \\
\hline 67 & & & & $\mathrm{c}$ & & & & & & & & & & \\
\hline 75 & & & & & & & & & & & $\mathrm{a}$ & & & \\
\hline \multicolumn{6}{|c|}{$\begin{array}{l}\mathrm{b}=\text { Model validation }-\mathrm{SCNI} \\
\mathrm{c}=\text { Model fitting }-\mathrm{SCVI}\end{array}$} & \multicolumn{8}{|c|}{$\begin{array}{l}\mathrm{e}=\text { Intermediate pressure study }-\mathrm{SCVI} \\
\mathrm{f}=\text { Injection superheat study }-\mathrm{SCVI}\end{array}$} & \\
\hline
\end{tabular}


a)

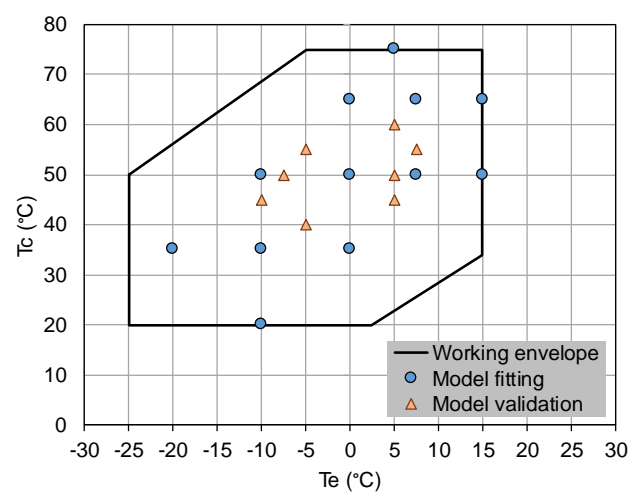

b)

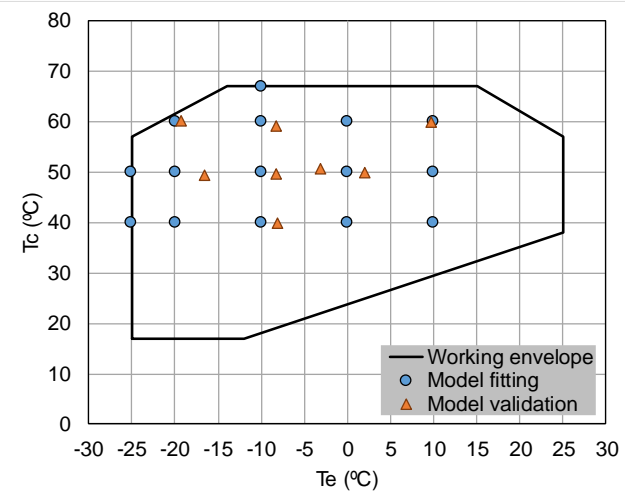

Fig. 0.5 Compressor working envelope and test points for the scroll compressors. a) SCNI working with R-290. b) SCVI working with R-407C.

\section{Results and discussion}

\subsection{Non-injected scroll compressors}

Fig. 5.6 shows the experimental compressor efficiencies of the SCNI as a function of the pressure ratio. This figure shows a maximum compressor efficiency for a pressure ratio of around 3 for all compressor sizes. The compressor efficiency decreasing is more significant for lowpressure ratios $(<3)$. Regarding the volumetric efficiency, the scroll compressors present high volumetric efficiency, above 0.85 for all operating conditions. The volumetric efficiency decreases almost linearly as a function of the pressure ratio. The larger compressors (C30 and C38) present higher volumetric efficiency than the smaller compressors (up to 3\% for highpressure ratios).

The adjusted model parameters for each compressor are shown in Table 5.3. The built-in volume ratio $(\varepsilon)$ of the compressors is around 3 . This value has a physical meaning that can explain the shape of the compressor efficiency curve of Fig. 5.6a, where the maximum efficiency is around a pressure ratio of 3 , that is corresponding to the adapted compressor conditions. 
a)

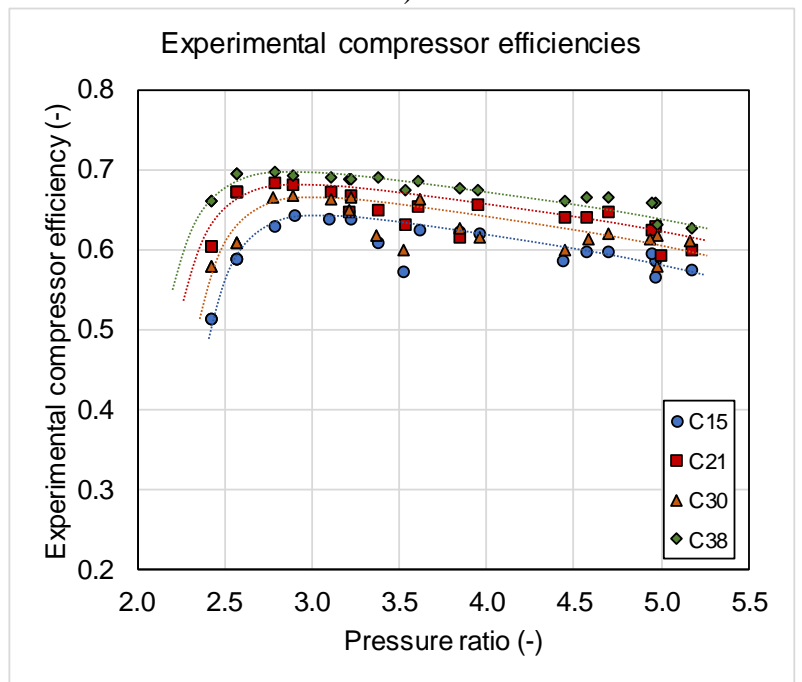

b)

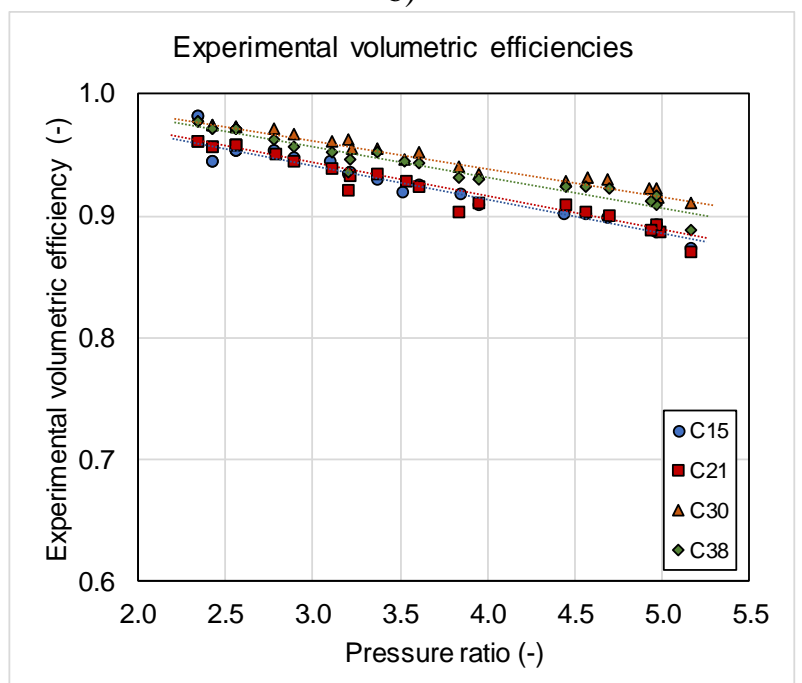

Fig. 0.6 Experimental results of SCNI working with R-290. a) Overall compressor efficiencies b) Volumetric efficiencies

The equivalent leak area $\left(\mathrm{A}_{\text {leak }}\right)$ is increased according to the compressor size, as the swept volume increases, the $\mathrm{A}_{\text {leak }}$ increases. The $\mathrm{UA}_{\mathrm{amb}}$ values for all compressors are small; therefore, experimental data of discharge temperature can be dispensed for the determination of UA and the estimation of the discharge temperature. This model feature is useful when adjusting the model from catalog data, in which discharge temperature data is not available.

Table 0.3 Parameter values for the SCNI under study.

\begin{tabular}{|c|c|c|c|c|c|}
\hline \multirow{2}{*}{\multicolumn{2}{|c|}{ Parameter }} & \multicolumn{4}{|c|}{ Compressor model } \\
\hline & & \multirow{2}{*}{$\begin{array}{l}\mathbf{C 1 5} \\
3.16\end{array}$} & \multirow{2}{*}{$\begin{array}{l}\text { C21 } \\
2.97\end{array}$} & \multirow{2}{*}{$\begin{array}{l}\text { C30 } \\
3.14\end{array}$} & \multirow{2}{*}{$\begin{array}{l}\text { C38 } \\
2.94\end{array}$} \\
\hline$\varepsilon$ & $(-)$ & & & & \\
\hline $\mathrm{K}_{1}$ & $\left(\mathrm{~K}^{-1}\right)$ & 0.923 & 0.92 & 0.928 & 0.928 \\
\hline $\mathrm{K}_{2}$ & $\left(\mathrm{~m}^{1 / 5}\right)$ & 0.075 & 0.08 & 0.082 & 0.085 \\
\hline $\mathrm{K}_{3}$ & $\left(m^{-4}\right)$ & $2.138 \mathrm{E}+06$ & $1.898 \mathrm{E}+06$ & $1.864 \mathrm{E}+06$ & $1.369 \mathrm{E}+06$ \\
\hline $\mathrm{K}_{4}$ & $\left(m^{-4}\right)$ & $5.755 \mathrm{E}+08$ & 4.167E+08 & $3.620 \mathrm{E}+08$ & $2.205 \mathrm{E}+08$ \\
\hline
\end{tabular}




\begin{tabular}{cc|c|c|c|c}
$\mathrm{K}_{5}$ & $(-)$ & 70 & 69.8 & 75 & 70.68 \\
$\mathrm{~K}_{6}$ & $(\mathrm{~J} \mathrm{~s})$ & 127.1 & 126 & 129 & 127 \\
$\eta_{\mathrm{el}}$ & $(-)$ & 0.86 & 0.87 & 0.85 & 0.88 \\
$\mathrm{UA}_{\text {amb }}$ & $\left(\mathrm{W} \mathrm{K} \mathrm{K}^{-1}\right)$ & 0.5 & 0.55 & 0.55 & 0.55 \\
$\mathrm{~A}_{\text {leak }}$ & $\left(\mathrm{m}^{2}\right)$ & $6.634 \mathrm{E}-06$ & $7.758 \mathrm{E}-06$ & $1.177 \mathrm{E}-05$ & $1.246 \mathrm{E}-05$ \\
\hline
\end{tabular}

The pressure drop coefficients $\left(\mathrm{K}_{3}\right.$ and $\left.\mathrm{K}_{4}\right)$ decreases as the compressor size increases. The rest of the model parameters are quite similar. These results point in the direction that the model coefficients have a relationship with the internal physics of the compressor and could be an indication of the consistency and robustness of the developed model.

\subsubsection{Model validation}

In this section, the validation results of the compressor model are presented. As it was mentioned in section 5.3, the model parameters were adjusted by using 12 experimental points. The model validation is performed by using 8 experimental points which were not considered in the fitting process. The fitting and validation points are represented in all figures.

Fig. 5.7 shows the validation of the compressor efficiencies for all compressor sizes studied. The model results present a deviation lower than $\pm 5 \%$ for the majority of the points for the compressor efficiency, and a deviation lower than $\pm 3 \%$ for the volumetric efficiency.

a)

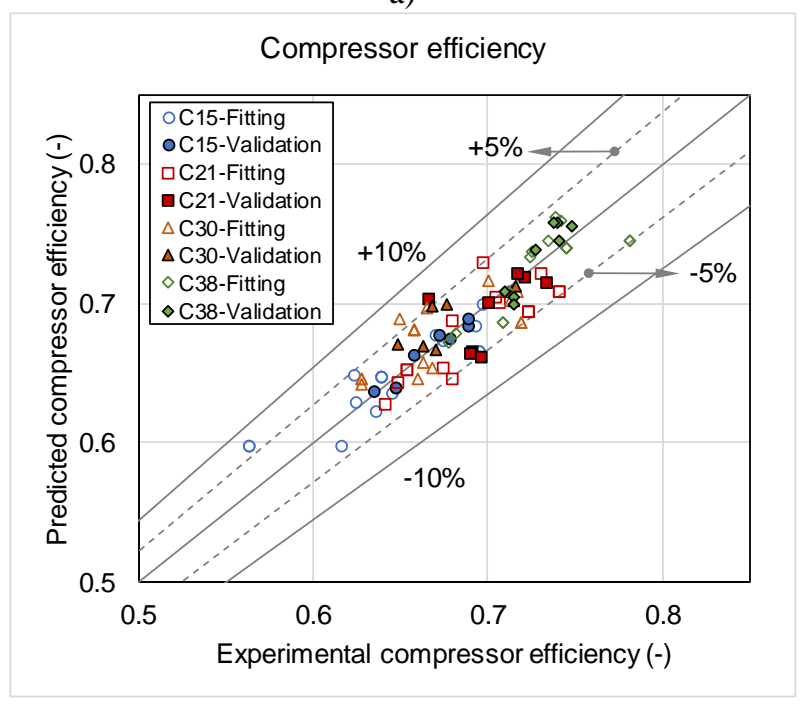

b) 


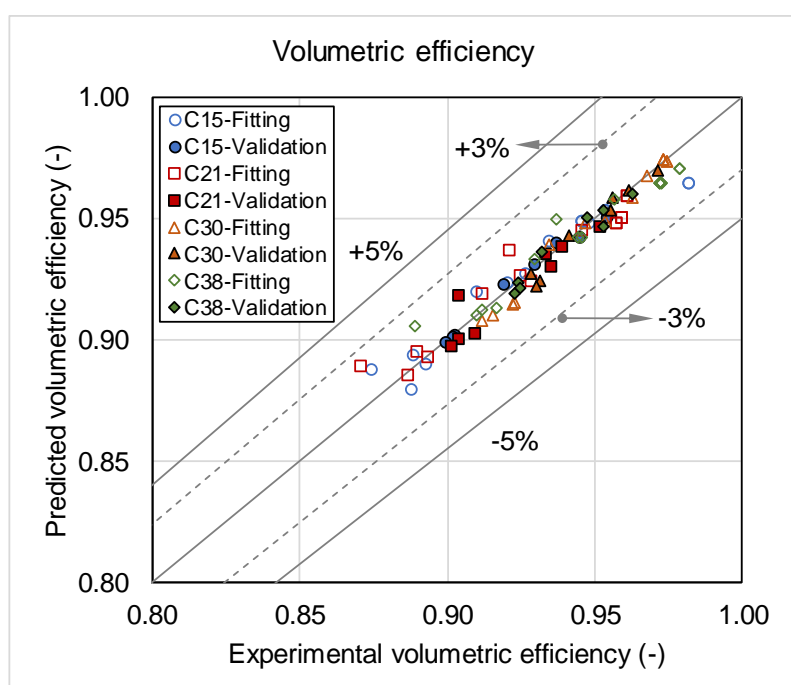

Fig. 0.7 Comparison between experimental and predicted efficiencies of a series of SCNI working with R-290. a) Overall compressor efficiencies. b) Volumetric efficiencies

The compressor model is able to estimate with good accuracy the mass flow rate, the compressor power input and the discharge temperature. Fig. 5.8 presents the comparison between the experimental and predicted results of the compressor model. For all compressor sizes, mass flow rate, compressor power input, and discharge temperature are predicted with a deviation lower than $\pm 3 \%, \pm 5 \%$, and $\pm 3 \mathrm{~K}$, respectively. The accurate estimation of the discharge temperature is an important advantage of this model, due to this data is used to calculate the heating capacity in heat pumps and it can be useful to determine the operating limits of a given compressor, taking into account the possible degradation of the refrigerant at high temperatures.

Overall, according to figures 5.7 and 5.8, the results obtained for the validation points do not have a greater deviation than the results obtained for the fitting points.

a)

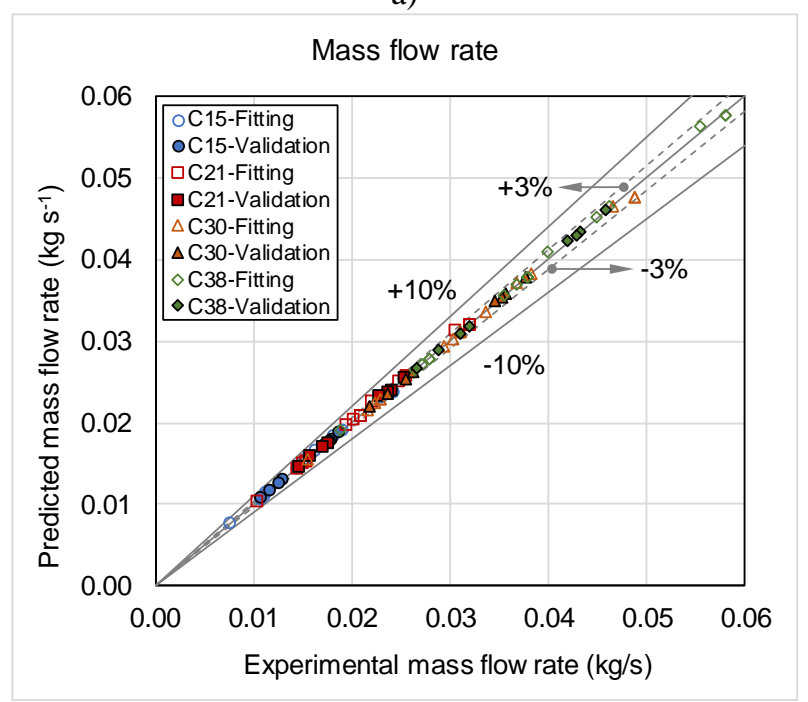


b)

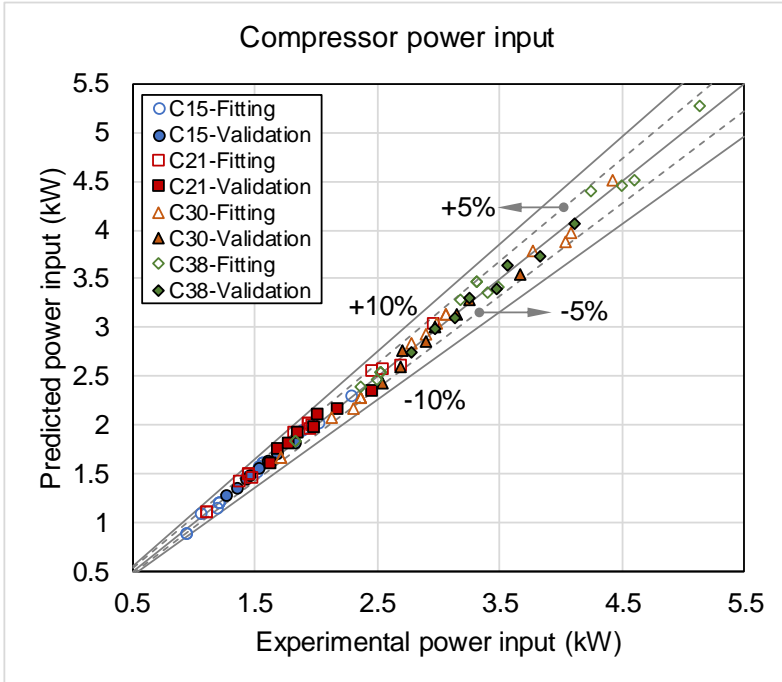

c)

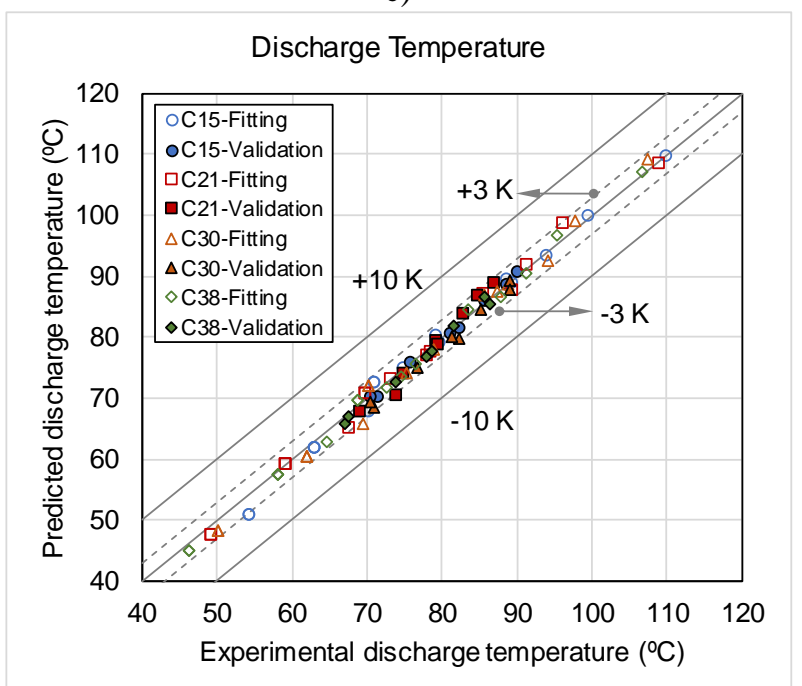

Fig. 0.8 Comparison between experimental and predicted results of a series of SCNI working with R290. a) Mass flow rate. b) Compressor power input. c) Discharge temperature.

\subsubsection{Compressor losses}

Since the model has been developed under the philosophy of associating each model parameter with each possible loss of energy in the compression process, it can be thought that, from the physical point of view, the losses calculated from the model can save some relationship with the real losses that may exist in the compression process. Therefore, it is possible to try to estimate losses in an approximate way, taking into account the intrinsic limitations of a semiempirical model. In this context, this section shows the estimation of the energy losses in the compressor based on the model results.

The losses associated with the compression process are estimated as the difference between the actual compression work $\left(\dot{W}_{4^{\prime}-5}\right)$ and the compression work calculated considering an isentropic compression process from the point 4' and 5. In order to analyze the compressor work losses independently of the compressor size, the normalized losses associated with the compression process as a function of the pressure ratio, see Fig. 5.9a. This figure shows that the compression losses has a minimum at a pressure ratio around 3 . This pressure ratio is the 
corresponding pressure ratio to the built-in volume ratio of the compressors identified previously. Therefore, Fig. 5.9a shows the losses associated to the over and under compression. The effect of the no-adaption of the built-in volume ratio is more severe at lower pressure ratios (overcompression), as observed by Winandy et al. (2002). This effect can explain the slope of the compressor efficiency curves, where the decreasing of the efficiency is more severe at lower pressure ratios for all the compressors studied.

Fig. 5.9b represents the estimated pressure drop in the suction and discharge ports. The pressure losses in the suction are very small; this can be explained by the fact that scroll compressors do not have a suction valve. On the other hand, the discharge pressure losses are dependent on the compressor size; hence, they are higher for larger compressor sizes. Moreover, the discharge pressure losses are higher for low-pressure ratios due to these losses were modeled assuming a dependence on the square of the gas velocity. Consequently, as the mass flow is greater at low-pressure ratios, the pressure losses in the discharge will be greater under these working conditions. 
a)

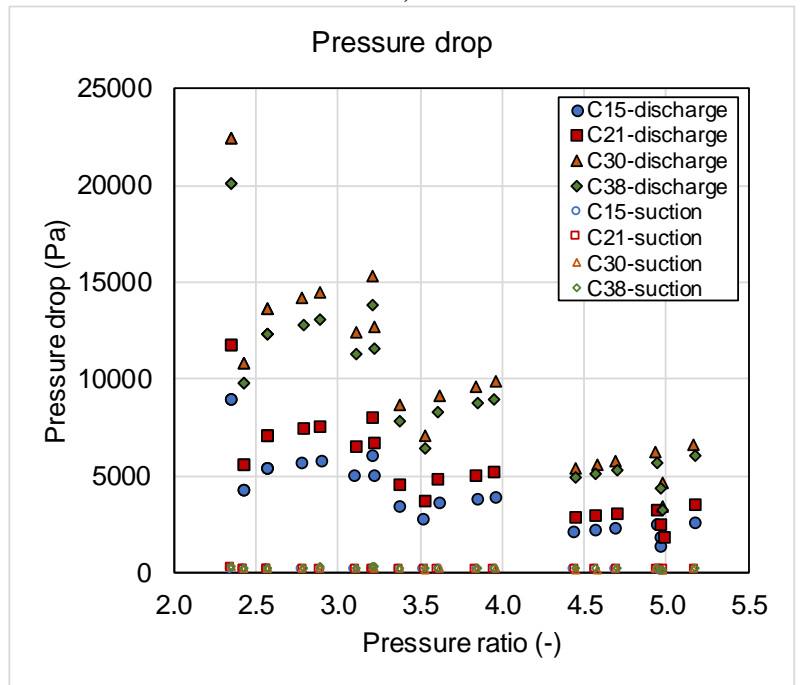

b)

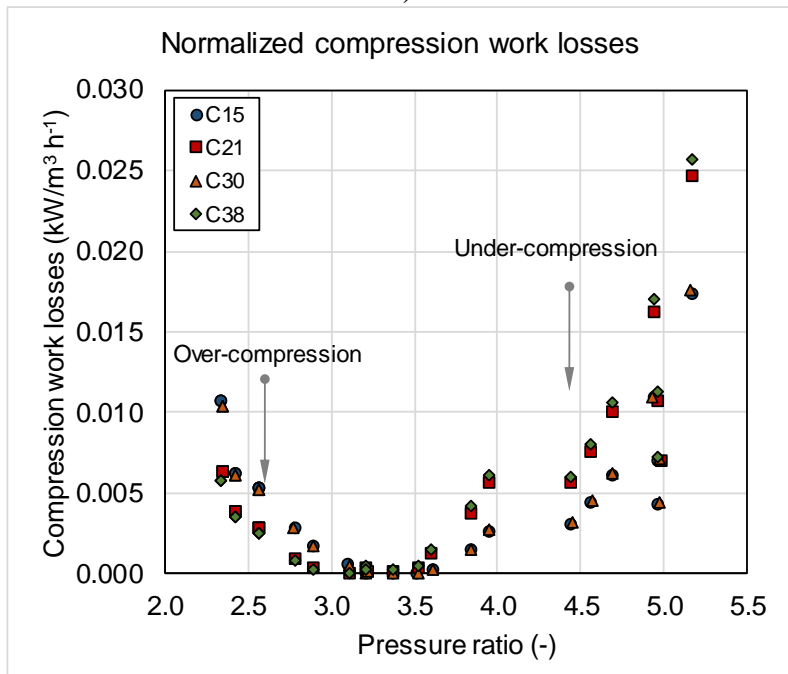

Fig. 0.9 a) Losses associated with the compression process. b) Pressure drop estimation.

Fig. 5.10a shows the temperature increase of the refrigerant at the suction as a function of the pressure ratio. Motor cooling and mechanical loss dissipation play an important role in the vapor heating in the suction. The superheat is greater for large pressure ratios and it is more important for smaller compressors. On the other hand, the temperature increase in the suction by heat transfer from the discharge plenum is small (up to $3 \mathrm{~K}$ for pressure ratios of 5). This can be explained by the good separation between the hot zone of the discharge plenum and the cold suction zone that scroll compressors have, in comparison with other compressor technologies such as piston compressors (Navarro-Peris et al., 2015).

Fig. 5.10b depicts the percentage of leaks with respect to the total mass flow rate and the corresponding temperature increase of the refrigerant in the suction, both as a function of pressure ratio. Although the equivalent area of leakage is greater for large compressors (see Table 5.3), Fig. 5.10b shows a higher percentage of leaks for small compressors, indicating a greater proportion of leaks with respect to the total mass flow of the compressor. In addition, leaks have a clear upward trend with the pressure ratio; consequently, the increase in suction temperature is greater at higher compression ratios. 
It is important to note that the results presented on compressor losses are only indicative. The model is not intended to provide actual values of losses within the compressor because the results of the model come from an adjustment of parameters based on experimental data. Although the equations of the model represent physical phenomena, the results of a semi-empirical model will depend on the fitting accuracy of the parameters, unlike the geometric models that include in the equations real dimensions of the internal components of the machine. However, the present model is useful for the accurate estimation of the compressor performance under different working conditions that allows evaluating the performance of heat pumps or cooling systems, with few input data of the compressor (available in catalogs). Another possible application of the model is the evaluation of the operation of compressors or diagnosis, that is, to identify if a compressor has some malfunctions when the estimated values of losses are different from the expected tendencies according to the model results. 
a)

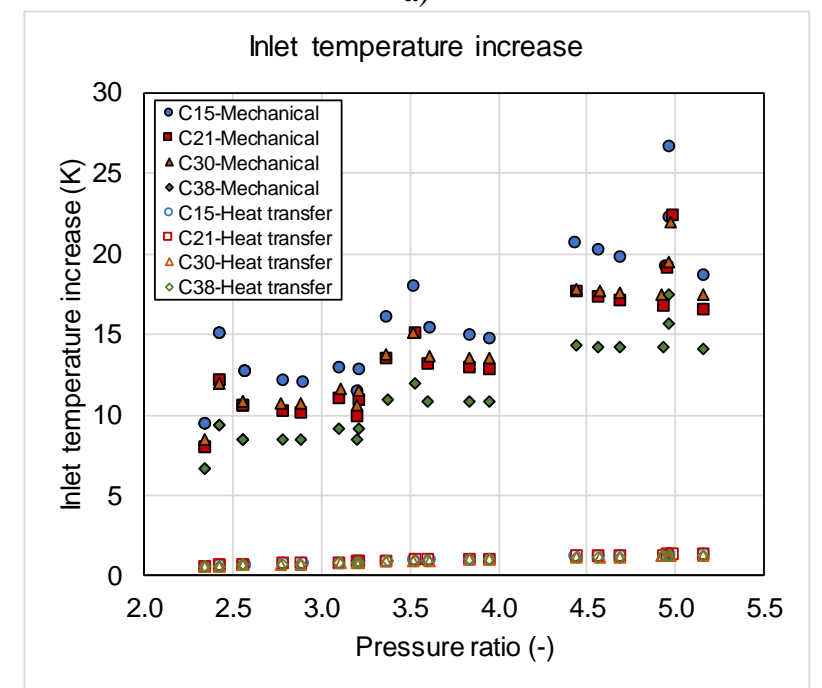

b)

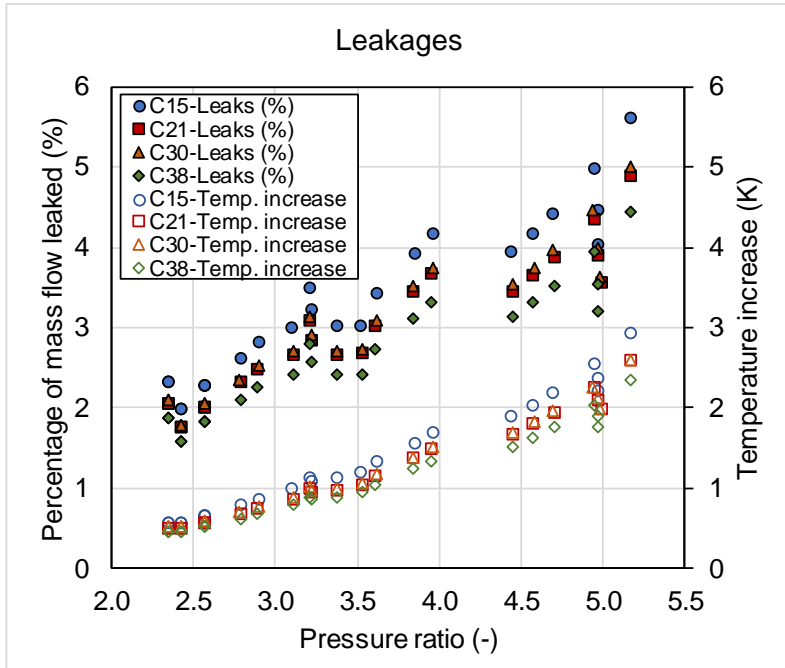

Fig. 0.10 a) Inlet temperature increase as a function of the pressure ratio. b) Percentage of mass flow leaked and temperature increase due to leaks as a function of the pressure ratio. 


\subsubsection{Sensitivity analysis}

A sensitive analysis was performed by varying the identified parameters between $\pm 5 \%$, following the reference (Cuevas et al., 2010). The response of the model was evaluated respecting the compressor efficiencies through the ratio error/error ${ }_{\min }$ as a function of the ratio between the actual and the identified parameter in Fig. 5.11. Error $_{\text {min }}$ represents the minimum value reached by the function error (Eq. (5.22)) evaluated with the identified model parameters, but considering one of the compressor efficiencies at a time.

According to Fig. 5.11a, for the compressor efficiency estimation, the model is quite sensitive to the $\eta_{\mathrm{el}}$ and $\varepsilon$, followed by $\mathrm{K}_{1}$, the mechanical losses parameters $\left(\mathrm{K}_{5}\right.$, and $\left.\mathrm{K}_{6}\right)$ and $\mathrm{A}_{\text {leak }}$, whereas the other parameters slightly disturb the response of the model against this variation. Regarding the volumetric efficiency estimation, the model is quite sensitive to the $\eta_{\mathrm{el}}$ and $\mathrm{K}_{1}$, followed by the $\mathrm{A}_{\text {leak }}, \varepsilon, \mathrm{K}_{5}$, and $\mathrm{K}_{6}$, whereas the rest of the parameters are less influencing. These results are the expected because the volumetric efficiency is highly affected by the vapor heating in the suction (Eq. (5.11)) and the leaks. Overall, all lines illustrated in Fig. 5.11 have their minimum when the abscissa is equal to 1 , which indicates that the set of identified parameters provided in Table 5.3 lead to the global minimum of relative error function defined in Eq. (5.22). 
a)

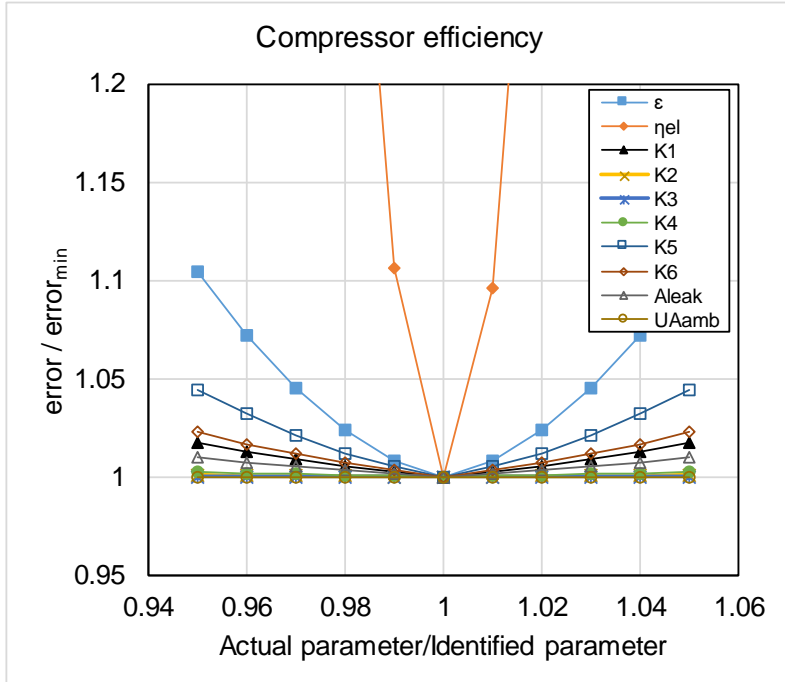

b)

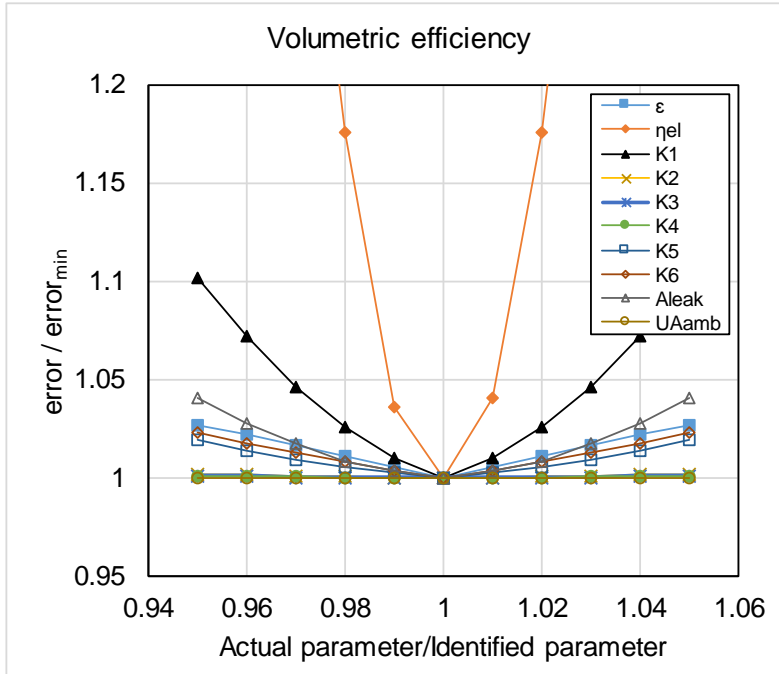

Fig. 0.11 Sensitivity analysis of the compressor model to the identified parameters (SCNI-C38). a) Overall compressor efficiency b) Volumetric efficiency 


\subsection{Vapor injected scroll compressor}

Fig. 5.12a shows the compressor and volumetric efficiencies of the SCVI as a function of the pressure ratio. The volumetric efficiency is higher than 0.8 for any operating point. The compressor efficiency varies from 0.5 to 0.635 . This figure shows a maximum compressor efficiency for a pressure ratio of around 3. For pressure ratios higher than 9 , the compressor efficiency decreases to 0.5 .

a)

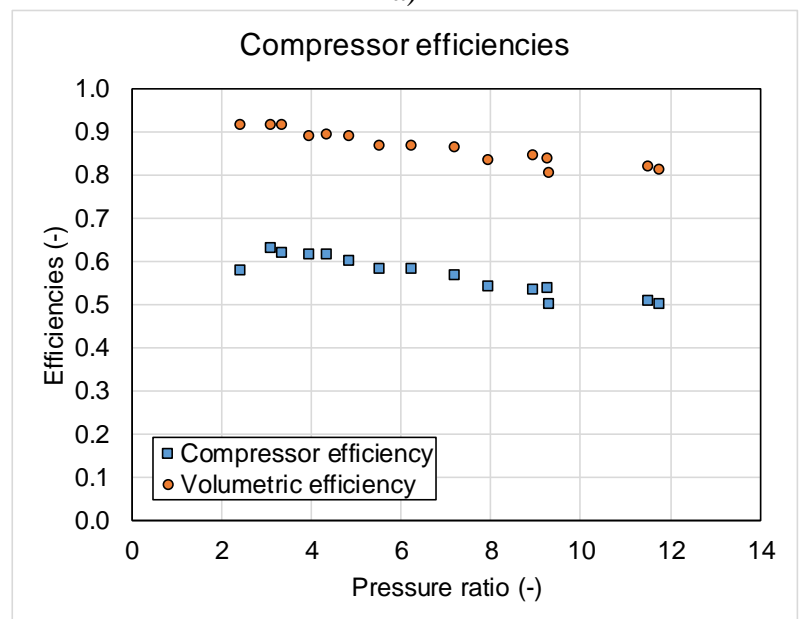

b)

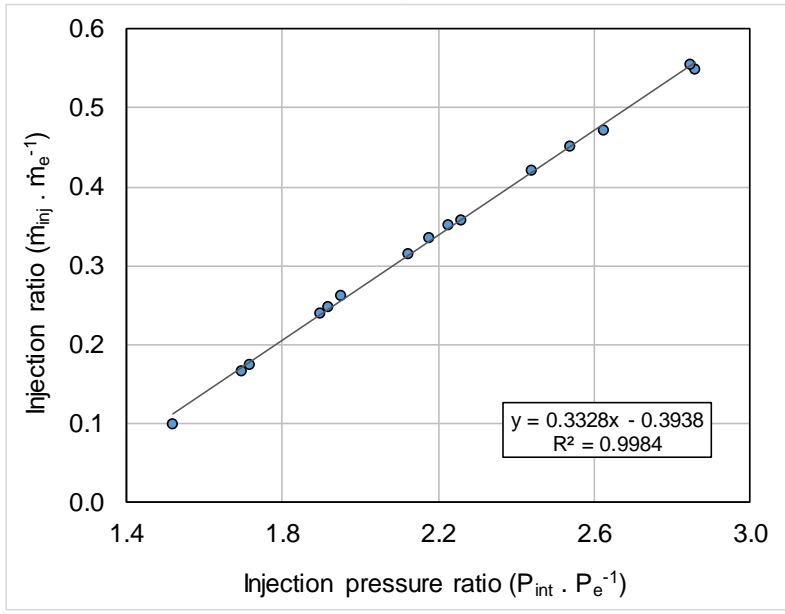

Fig. 0.12 a) Compressor efficiency and volumetric efficiency of SCVI as a function of pressure ratio.

b) Injection ratio as a function of the injection pressure ratio.

As posed in section 5.2.6, the injection ratio $\left(\dot{m}_{i n j} / \dot{m}_{e}\right)$ and the intermediate pressure ratio $\left(P_{\text {int }} / P_{e}\right)$ is correlated by the Eq. (5.23). Fig. 5.12b depicts the injection ratio as a function of the injection pressure ratio for the 15 points of the compressor working envelope (see Table 5.2). This figure shows the linear dependence between the two ratios, where the coefficients $A=-0.3938$ and $\mathrm{B}=0.3328$ with an $\mathrm{R}$-square correlation factor higher than 0.99 . These two parameters are used in the SCVI model to calculate the injection mass flow rate for a given suction and injection external conditions (pressure and superheat). The rest of the model parameters are adjusted using the experimental data of the compressor and are listed as follows: 
- $\mathrm{K}_{1}=0.92\left(\mathrm{~K}^{-1}\right)$

- $\mathrm{K}_{2}=0.026\left(\mathrm{~m}^{1 / 5}\right)$

- $\mathrm{K}_{3}=6.16 \mathrm{E}+06\left(\mathrm{~m}^{-4}\right)$

- $\mathrm{K}_{4}=1.97 \mathrm{E}+09\left(\mathrm{~m}^{-4}\right)$
- $\mathrm{K}_{6}=84.25(\mathrm{~J} \mathrm{~s})$

- $\eta_{\mathrm{el}}=0.856(-)$

- $\mathrm{UA}_{\mathrm{amb}}=0.81\left(\mathrm{~W} \mathrm{~K}^{-1}\right)$

- $\mathrm{A}_{\text {leak }}=8.425 \mathrm{E}-06\left(\mathrm{~m}^{2}\right)$

\subsubsection{Model validation}

The SCVI model parameters were fitted with 15 experimental data (Fig. 5.5b), and the model validation is performed by using 8 experimental points (labels " $\mathrm{d}$ " in Table 5.2) which were not considered in the fitting process. The fitting and validation points are represented in all figures.

Fig. 5.13 shows the model validation of the compressor efficiencies. The model results present a deviation lower than $\pm 5 \%$ for the compressor and volumetric efficiencies. 
a)

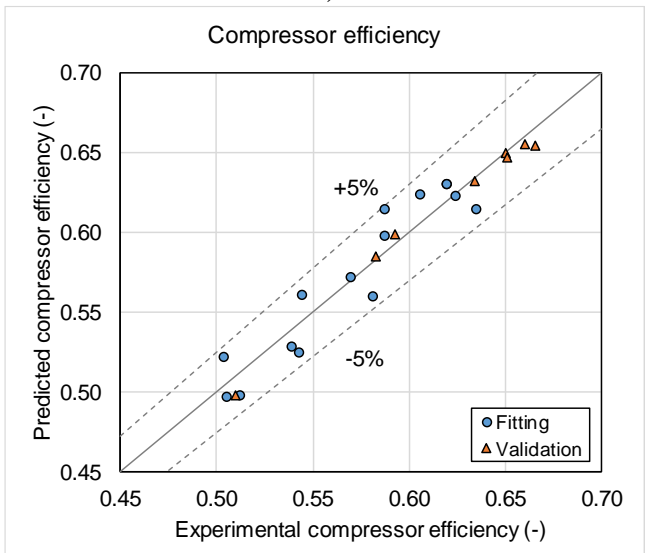

b)

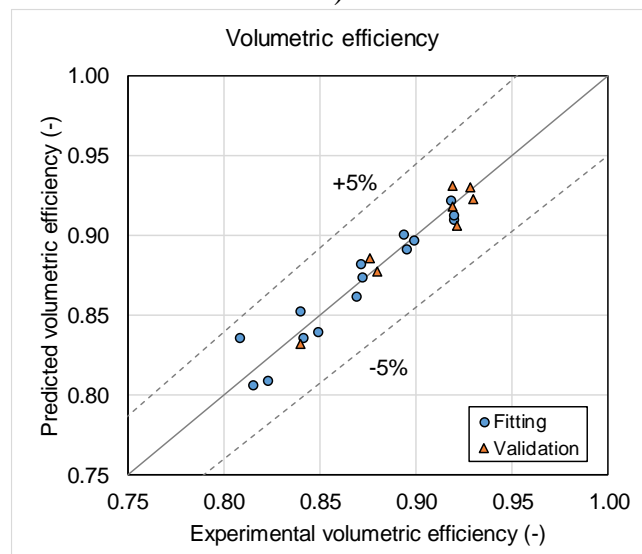

Fig. 0.13 Comparison of experimental and predicted efficiencies of the SCVI working with R-407C. a) Overall compressor efficiency. b) Volumetric efficiency.

All the compressor parameters are also calculated in order to evaluate the model response. Fig. 5.14 illustrates the comparison of predicted and experimental results of the suction mass flow rate (a), injection mass flow rate (b); compressor power input (c) and discharge temperature (d). All predicted parameters showed a correct agreement with the experimental results; the maximum deviation does not exceed $\pm 2 \%, \pm 4 \%, \pm 5 \%$, and $\pm 4 \mathrm{~K}$ respectively in the majority of the evaluated points.

In order to compare the results of the present model with results calculated from empirical correlations of the literature (Tello-Oquendo et al., 2017), the maximum and average deviation of the output parameters of the 8 validation points were calculated. Results are shown in Table 5.4. 
a)

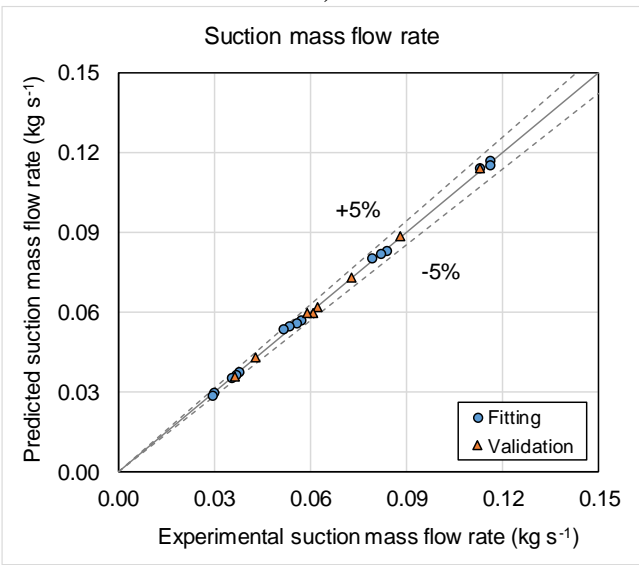

c)

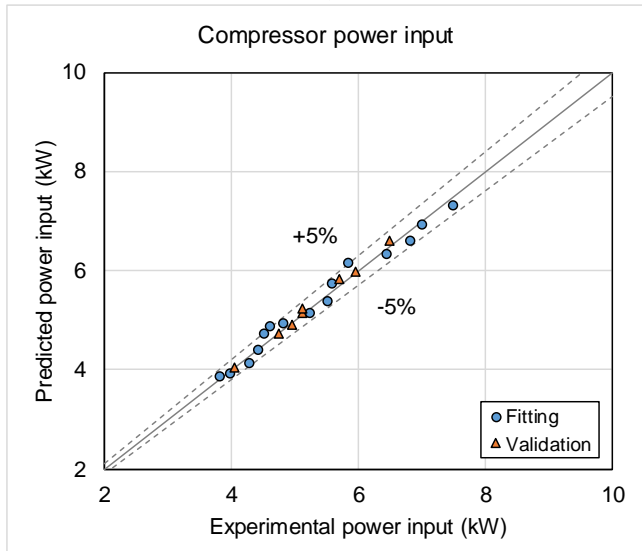

b)

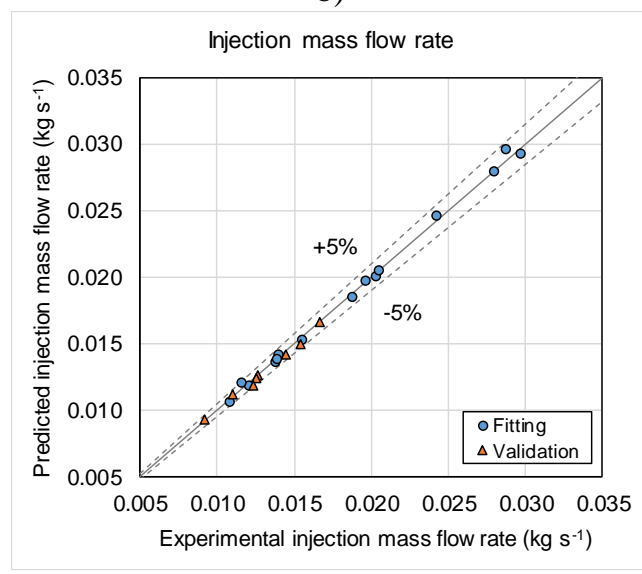

d)

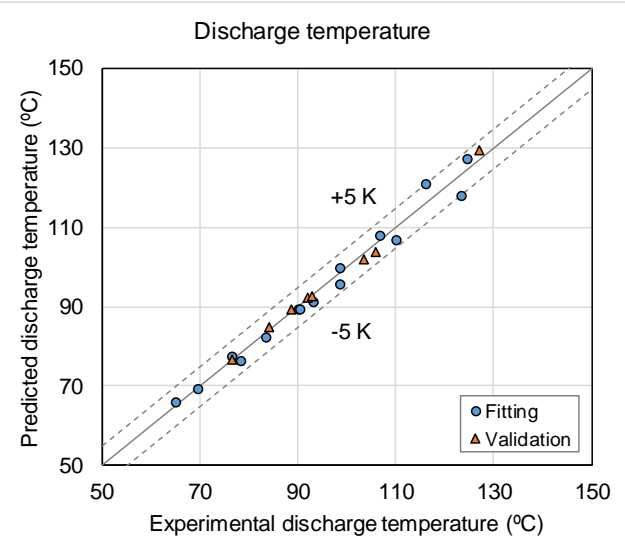

Fig. 0.14 Comparison of experimental and predicted data of the SCVI working with R-407C.

Table 0.4 Deviations of the model results.

\begin{tabular}{c|c|c|c|c|c}
\hline \multirow{2}{*}{ Model type } & Relative deviations & \multicolumn{3}{|c}{ Compressor parameter } \\
\cline { 2 - 6 } & (Calc.-Test)/Test x 100 & $\dot{\mathbf{E}}$ & $\dot{\mathbf{m}}_{\mathbf{e}}$ & $\dot{\mathbf{m}}_{\mathbf{i n j}}$ & $\mathbf{T}_{\text {dis }}$ \\
\hline Empirical correlations & Maximum (\%) & -4.40 & -1.80 & -2.91 & - \\
(Tello-Oquendo et al., 2017) & Average (\%) & -1.08 & -0.79 & -0.95 & - \\
\hline \multirow{2}{*}{ Present model } & Maximum (\%) & 4.47 & -1.95 & -3.97 & $3.24 \mathrm{~K}$ \\
& Average (\%) & 1.49 & -0.78 & -1.04 & $0.96 \mathrm{~K}$ \\
\hline
\end{tabular}

Overall, the estimation of compressor parameters from empirical correlations is more accurate than the results of the proposed semi-empirical model. However, empirical correlations have several restrictions. Firstly, it is not possible to estimate the discharge temperature of the compressor from empirical models and less from catalog data, because information on heat losses of the compressor to ambient is needed. This information depends on physical and functioning conditions of the compressor, which are not considered in the empirical correlations. In addition, empirical correlations are valid only for input data values that are within the fitting range of the correlations, losing predictive capability under conditions outside the fitting range.

On the other hand, empirical models like AHRI polynomials, need at least 10 parameters for mass flow rate estimation, 11 parameters for compressor power input estimation and 2 additional parameters for injection mass flow rate correlation (Tello-Oquendo et al., 2017). Conversely, the present model uses only 12 parameters, and the results present a good agreement with the experimental data, with the advantage of having more information such the discharge 
temperature. A smaller number of model parameters implies a smaller number of test points needed to adjust the model.

\subsubsection{Model response to the intermediate pressure variation}

The methodology used to characterize the SCVI allows testing the compressor varying the intermediate pressure and maintaining the injection superheat (Tello-Oquendo et al., 2017). Unlike the recently published standard EN 13771-1 (2016), the methodology used in the present work allows adjusting the intermediate conditions of the compressor (injection mass flow rate and intermediate pressure) independently of the injection mechanism used in the system (internal heat exchanger or flash tank).

In the case of a system with an internal heat exchanger, the intermediate pressure at which the compressor works is conditioned by the heat transfer capacity of the internal heat exchanger and by the subcooling at the condenser outlet. If it is necessary to maintain a constant injection superheat for different intermediate pressures, the size of the internal heat exchanger must be different, which is impossible from the practical point of view.

In order to evaluate the model response to the intermediate pressure variation, the SCVI was tested under different levels of intermediate pressure for each operating condition (labels "e" in Table 5.2); by acting the electronic expansion valve (EEV-1). The injection superheat was fixed to $5 \mathrm{~K}$ by controlling the flow of the water-glycol circuit (see Fig. 5.4).

Fig. 5.15 shows the predicted compressor parameters for several intermediate pressures. Fig. 5.15a illustrates a good agreement of the experimental and calculated injection mass flow rate values. The model prediction of the compressor power input and the discharge temperature is less accurate for intermediate pressure variations, a small divergence in the slope of the curve can be observed as a function of the intermediate pressure for some working points. This effect can be derived from the assumption of considering an isobaric mixture of the injection and suction mass flow rates at the intermediate pressure. Nevertheless, the maximum deviation of the compressor power input is $\pm 4 \%$ and $\pm 5 \mathrm{~K}$ for the discharge temperature, that are good results taking into account the simplicity of the model.

a)

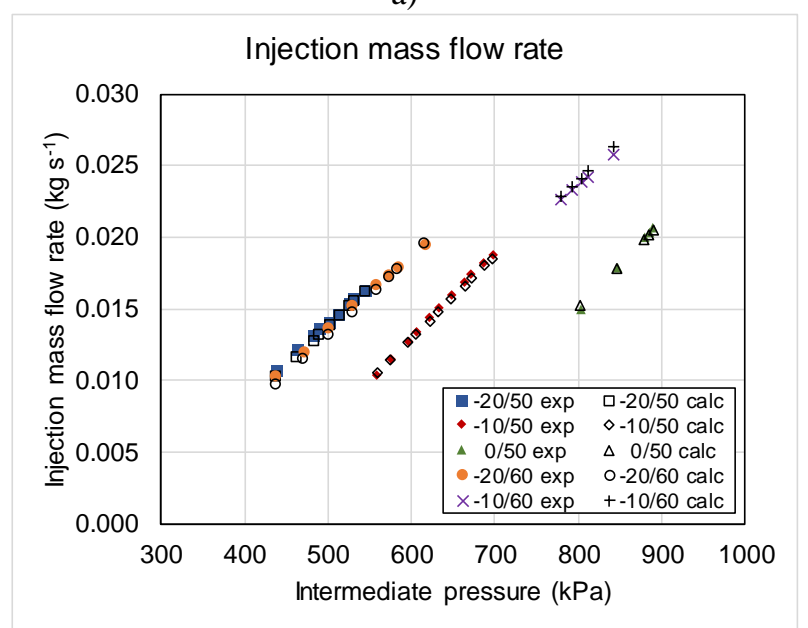


b)

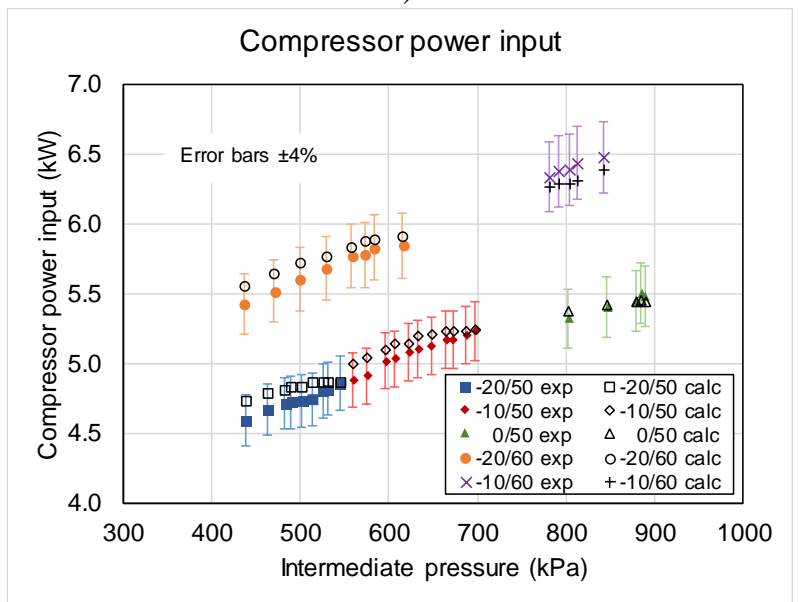

c)

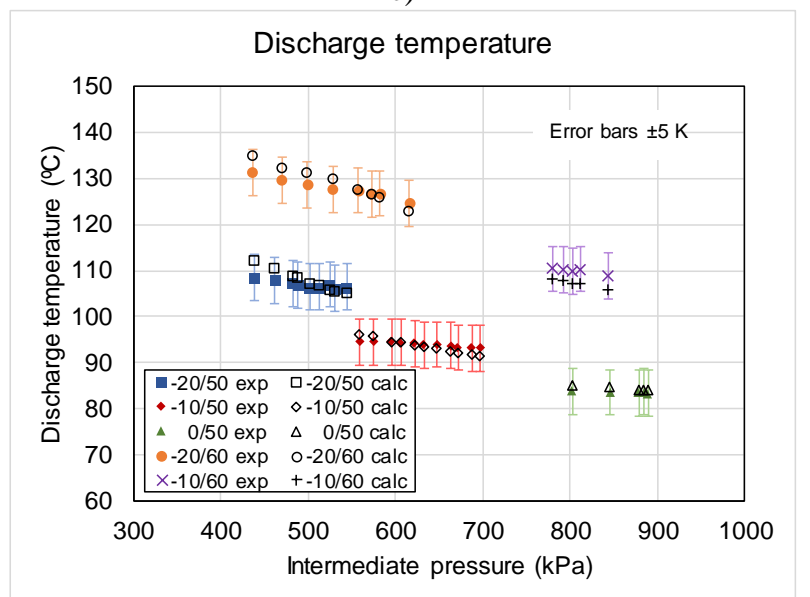

Fig. 0.15 Model response to the intermediate pressure variation.

\subsubsection{Model response to the injection superheat variation}

In order to analyze the model response to the injection superheat variation, three tests were performed at the working point $\left(\mathrm{T}_{\mathrm{e}}=-8{ }^{\circ} \mathrm{C}, \mathrm{T}_{\mathrm{c}}=50^{\circ} \mathrm{C}\right)$. The experimental results are presented in Table 5.5. The comparison of the experimental and predicted data of the SCVI are illustrated in Fig. 5.16. This figure shows a good accuracy prediction on the injection mass flow rate, compressor power input and discharge temperature with a maximum deviation of $\pm 3 \%, \pm 3 \%$, and $\pm 2 \mathrm{~K}$ respectively.

Table 0.5 Experimental results of the SCVI working with several injection superheats.

\begin{tabular}{c|c|c|c|c|c}
\hline $\mathbf{S H}_{\text {inj }}(\mathbf{K})$ & $\mathbf{S H}(\mathbf{K})$ & $\mathbf{P}_{\text {int }}(\mathbf{k P a})$ & $\dot{\mathbf{m}}_{\text {inj }}\left(\mathbf{k g ~ s}^{\mathbf{- 1}}\right)$ & $\dot{\mathbf{E}}(\mathbf{k W})$ & $\mathbf{T}_{\text {dis }}\left({ }^{\circ} \mathbf{C}\right)$ \\
\hline 2.55 & 10.76 & 632.00 & 0.01274 & 4.94 & 91.50 \\
7.82 & 10.47 & 630.00 & 0.01255 & 4.96 & 92.00 \\
15.90 & 8.71 & 597.80 & 0.01099 & 4.78 & 91.92 \\
\hline
\end{tabular}



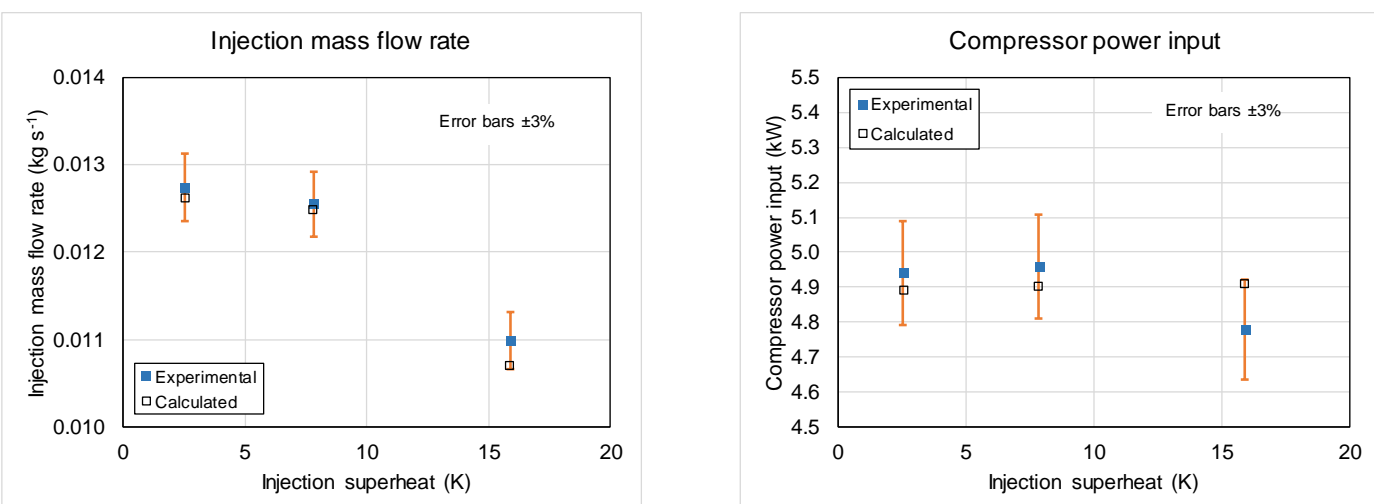

c)

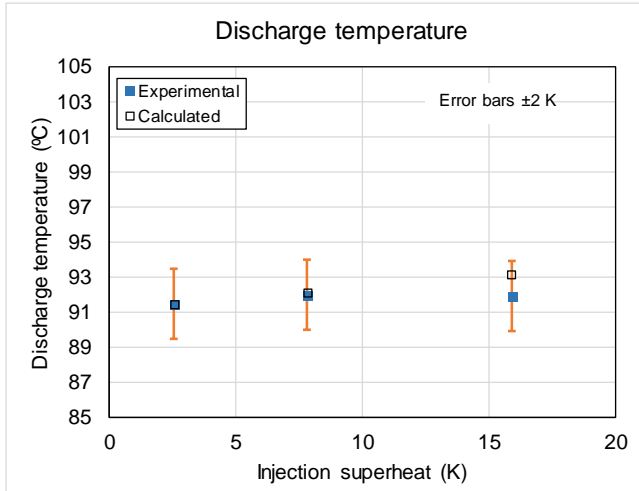

Fig. 0.16 Model response to the injection superheat variation.

The results shown in sections 5.4.2.1-5.4.2.3 demonstrate the capability of the model to estimate the parameters of the SCVI under different working conditions than those used for the model fitting. In practical cases, the proposed model is useful for evaluating the performance of heat pumps and cooling systems under various operating conditions.

It should be noted that semi-empirical models, by their nature, do not provide detailed information on the internal functioning of the compressor, as geometrical models do. Nevertheless, the objective of this work is to provide a simple tool to determine the performance of scroll compressors, in order to be adjusted from data that can be easily obtained from the manufacturer catalogs or from experimental measurements, and be able to predict the compressor performance with good precision to other intermediate conditions (intermediate pressure and injection superheat).

\section{Conclusions}

A semi-empirical model of the scroll compressors is presented. The model takes into account the ideal evolution of the refrigerant throughout the compressor and considers the main sources of losses in the compression process. This model has ten empirical parameters, which have a direct physical interpretation. These parameters can be obtained from some experimental or catalog data. In addition, a simplified methodology to extend the compressor model to vaporinjection scroll compressor is proposed. The model was validated with experimental data. A series of four non-injected scroll compressors of different capacities were tested in a calorimetric test bench using R-290, and a scroll compressor with vapor-injection was tested using R-407C. The following conclusions can be drawn from the study: 
- The decreasing of the compressor efficiency is more significant when the compressor works under over-compression conditions. The adjusted parameters are similar for the four compressors, except for the leakage area and the pressure drop parameters.

- The sensitive analysis of the model parameters indicates that the compressor efficiency estimation is quite sensitive to the electric motor efficiency, the built-in volume ratio, and the mechanical losses parameters, while the volumetric efficiency is also sensitive to the leakage area and the refrigerant heating due to the motor cooling and mechanical loss dissipation $\left(\mathrm{K}_{1}\right)$.

- For all SCNI, the model can reproduce the compressor efficiency and the volumetric efficiency with a deviation lower than $\pm 5 \%$ and $\pm 3 \%$ respectively under a wide range of operating conditions. In addition, the model estimates the mass flow rate, the compressor power input and the discharge temperature with a deviation lower than $\pm 3 \%, \pm 5 \%$, and $\pm 3 \mathrm{~K}$, respectively.

- Regarding the SCVI, the model can reproduce the compressor efficiency and the volumetric efficiency with a deviation lower than $\pm 5 \%$. In addition, the suction mass flow rate, the injection mass flow rate, the compressor power input and the discharge temperature are calculated with a deviation lower than $\pm 2 \%, \pm 4 \%, \pm 5 \%$, and $\pm 4 \mathrm{~K}$.

- The SCVI model was evaluated by varying the intermediate pressure and the injection superheat. Results show a good agreement of the experimental and predicted injection mass flow rate values, moreover, the model predicts the compressor power input and the discharge temperature with a maximum deviation of $\pm 4 \%$ and $\pm 5 \mathrm{~K}$, respectively. By varying the injection superheat, the model presents a good accuracy prediction on the injection mass flow rate, compressor power input and discharge temperature with a maximum deviation of $\pm 3 \%, \pm 3 \%$, and $\pm 2 \mathrm{~K}$, respectively.

- The model provides indicative information about the compressor losses; however, the results of the semi-empirical model will depend on the fitting accuracy of the parameters.

- The proposed model is useful for the accurate estimation of compressor performance under different working conditions. Therefore, the model can be reliably integrated into a system model to evaluate the performance of heat pumps or refrigeration systems, with few inputs data of the compressor (available in catalogs).

In summary, a semi-empirical model of scroll compressors has been developed, and a methodology to extend the model to vapor-injection compressors has been proposed. The developed model can be adjusted from catalog data and can predict the compressor performance with good accuracy in a wide range of operating conditions. An indicative estimation of the compressor losses can be obtained from the model results. Finally, despite the simplicity of the model, the compressor performance can be estimated with small deviations by varying the intermediate pressure and the injection superheat for a given working point, achieving versatility in the application of the model for various system configurations and working conditions.

\section{Acknowledgments}

Fernando M. Tello-Oquendo acknowledges the financial support provided by the CONVOCATORIA ABIERTA 2013-SEGUNDA FASE program, which was funded by the SENESCYT (Secretaría de Educación Superior, Ciencia, Tecnología e Innovación) (Grant No 2015-AR37665) of Ecuador. The authors would like to acknowledge the Spanish "MINISTERIO DE ECONOMIA Y COMPETITIVIDAD", through the project ref-ENE2017-83665-C2-1-P "Maximización de la eficiencia y minimización del impacto ambiental de bombas de calor para la descarbonización de la calefacción/ACS en los edificios de consumo casi nulo" for the given support. 


\section{References}

ARHI Standard 540, 2015. Standard For Performance Rating of Positive Displacement Refrigerant Compressors and Compressors Units. 2111 Wilson Boulevard, Suite 500 ArlingtonUSA VA 22201.

ASHRAE Handbook, 2008. HVAC Systems and Equipment. American Society of Heat- ing, Refrigerating and Air-Conditioning Engineers, Inc., Atlanta, USA.

Bell, I.H., Groll, E.A., Braun, J.E., King, G.B., Horton, W.T., 2012c. Optimization of a scroll compressor for liquid flooding. Int. J. Refrig. 35, 1901-1913.

Bell, I.H., Lemort, V., Groll, E.A., Braun, J.E., King, G.B., Horton, W.T., 2012a. Liq- uid-flooded compression and expansion in scroll machines-part I: model de- velopment. Int. J. Refrig. 35, $1878-1889$.

Bell, I.H., Lemort, V., Groll, E.A., Braun, J.E., King, G.B., Horton, W.T., 2012b. Liq- uid-flooded compression and expansion in scroll machines-part II: experimental testing and model validation. Int. J. Refrig. 35, 1890-1900.

Blunier, B., Cirrincione, G., Herve, Y., Miraouia, A., 2009. A new analytical and dy- namical model of a scroll compressor with experimental validation. Int. J. Refrig. 32, 874-891.

Bourdhouxhe, J.P., Grodent, M., Lebrun, J., Saavedra, K., Silva, A., 1994. A toolkit for primary HVAC system energy calculation-part 2: reciprocating chiller models. ASHRAE Trans. 100 (2), 774-786.

Byrne, P., Ghoubali, R., Miriel, J., 2014. Scroll compressor modelling for heat pumps using hydrocarbons as refrigerants. Int. J. Refrig. 41, 1-13.

Chen, Y., Braun, J.E., Groll, E.A., 2009. Modeling of hermetic scroll compressors: model development. HVAC\&R Res. 10 (2), 129-152.

Chen, Y., Halm, N.P., Groll, E.A., Braun, J.E., 2002a. Mathematical modeling of scroll compressors - part I: compression process modeling. Int. J. Refrig. 25, 731-750.

Chen, Y., Halm, N.P., Groll, E.A., Braun, J.E., 2002b. Mathematical modeling of scroll compressors - part II: overall scroll compressor modeling. Int. J. Refrig. 25, 751-764.

Cho, I.Y., Ko, S.B., Kim, Y., 2012. Optimization of injection holes in symmetric and asymmetric scroll compressors with vapor injection. Int. J. Refrig. 35 (4), 850-860.

Cuevas, C., Lebrun, J., Lemort, V., Winandy, E., 2010. Characterization of a scroll com- pressor under extended operating conditions. Appl. Therm. Eng. 30, 605-615.

Cuevas, C., Fonseca, N., Lemort, V., 2012. Automotive electric scroll compressor: test- ing and modeling. Int. J. Refrig. 35, 841-849.

Dardenne, L., Fraccari, E., Maggioni, A., Molinaroli, L., Proserpio, L., Winandy, E., 2015. Semiempirical modelling of a variable speed scroll compressor with vapour injection. Int. J. Refrig. $54,76-87$.

Duprez, M.E., Dumont, E., Frère, M., 2007. Modelling of reciprocating and scroll com- pressors. Int. J. Refrig. 30, 873-886.

Duprez, M.E., Dumont, E., Frère, M., 2010. Modeling of scroll compressors-improve- ments. Int. J. Refrig. 33, 721-728. 
EN 13771-1, 2016. Compressors and Condensing Units for Refrigeration - Perfor- mance testing and Test Methods - Part 1: Refrigerant compressors. European Committee for Standardization, Brussels, Belgium EN Standard.

EN 378, 2017. Refrigerating Systems and Heat Pumps - Safety and Environmental Requirements. European Committee for Standardization, Brussels, Belgium EN Standard.

EN 60079-14, 2014. Explosive Atmospheres - Part 14: Electrical installations design, Selection and Erection. European Committee for Standardization, Brussels, Bel- gium EN Standard.

EN 60079-15, 2010. Explosive Atmospheres - Part 15: Equipment protection By Type of Protection "n". European Committee for Standardization, Brussels, Belgium EN Standard.

EN 60335-2-34, 2013. Household and Similar Electrical Appliances - Safety - Part 2-34: Particular requirements for Motor-Compressors. European Committee for StandardizationEN Standard, Brussels, Belgium.

EN 60335-2-40:20 03/A13:2012, 20 03. Household and Similar Electrical Appliances - Safety Part 2-40: Particular requirements for Electrical Heat pumps, Air-Con- ditioners and Dehumidifiers. European Committee for Standardization, Brussels, Belgium EN Standard.

Giuffrida, A., 2014. Modelling the performance of a scroll expander for small or- ganic rankine cycles when changing the working fluid. Appl. Therm. Eng. 70, 1040-1049.

Klein, S.A., Alvarado, F.L., 2017. EES-Engineering Equation Solver. F-Chart Software, Madison, WI Academic Professional Version 10.091.

Lemmon, E., Huber, M., Mc Linden, M., 2010. NIST Standard Reference Database 23: Reference Fluid Thermodynamic and Transport Properties-Refprop. Na- tional Institute of Standards and Technology, Standard Reference Data Program, Gaithersburg Version 9.0.

Lemort, V., 2008. Contribution to the Characterization of Scroll Machines in Com- pressor and Expander Modes Ph.D. Thesis. University of Liège.

Navarro, E., Granryd, E., Urchueguía, J.F., Corberán, J.M., 2007a. A phenomeno- logical model for analyzing reciprocating compressors. Int. J. Refrig. 30, 1254-1265.

Navarro, E., Urchueguía, J.F., Corberán, J.M., Granryd, E., 2007b. Performance analysis of a series of hermetic reciprocating compressors working with R290 (propane) and R407C. Int. J. Refrig. 30, 1244-1253.

Navarro-Peris, E., Corberán, J.M., Ancik, Z.,2015. Evaluation of the potential re- covery of compressor heat losses to enhance the efficiency of refrigera- tion systems by means of thermoelectric generation. Appl. Therm. Eng. 89, 755-762.

Nellis, G., Klein, S., 2009. Heat Transfer, 1st ed. Cambridge University Press, New York.

Park, Y.C., Kim, Y., Cho, H., 2002. Thermodynamic analysis on the performance of a variable speed scroll compressor with refrigerant injection. Int. J. Refrig. 25, 1072-1082.

Press, W.H., Teukolsky, S.A., Vetterling, W.T., Flannery, B.P., 2007. Numerical Recipes: The Art of Scientific Computing, 3rd Ed. ed. Cambridge University Press, New York.

Schein, C., Radermacher, R., 2001. Scroll compressor simulation model. J. Eng. Gas Turb. Power. 123, 217-223. 
Sun, H., Hu, H., Wu, J., Ding, G., Li, G., Wu, C., Wang, X., Lv, Z., 2018. A theory-based explicit calculation model for variable speed scroll compressors with vapor in- jection. Int. J. Refrig. 88, 402-412.

Tello-Oquendo, F.M., Navarro-Peris, E., Gonzálvez-Maciá, J., 2017. New characteri- zation methodology for vapor-injection scroll compressors. Int. J. Refrig. 74, 526-537.

Tseng, C.H., Chang, Y.C., 2006. Family design of scroll compressors with optimiza- tion. Appl. Therm. Eng. 26, 1074-1086.

Wang, B., Shi, W., Han, L., Li, X., 2009a. Optimization of refrigeration system with gas-injected scroll compressor. Int. J. Refrig. 32, 1544-1554.

Wang, B., Shi, W., Li, X., 2009c. Numerical analysis on the effects of refrigerant in- jection on the scroll compressor. Appl. Therm. Eng. 29, 37-46.

Wang, B., Shi, W., Li, X., Yan, Q., 2008. Numerical research on the scroll compressor with refrigeration injection. Appl. Ther. Eng. 28, 4 40-4 49.

Winandy, E.L., Lebrun, J., 2002. Scroll compressors using gas and liquid injection: experimental analysis and modelling. Int. J. Refrig. 25, 1143-1156.

Winandy, E., Saavedra, C., Lebrun, J., 2002. Experimental analysis and simplified modelling of a hermetic scroll refrigeration compressor. Appl. Therm. Eng. 22, 107-120. 